\title{
HRTEM analysis of the high-temperature phases of the newly developed high-temperature Ni-base superalloy VDM 780 Premium
}

\author{
C. Ghica a , C. Solís ${ }^{\text {b, * }}$, J. Munke ${ }^{\text {b }}$, A. Stark ${ }^{\text {c }}$, B. Gehrmann ${ }^{\text {d }}$, M. Bergner ${ }^{\text {e }}$, J. Rösler ${ }^{\text {e }}$, \\ R. Gilles ${ }^{b}$
}

a National Institute of Materials Physics, 077125, Magurele, Romania

${ }^{\mathrm{b}}$ Heinz Maier-Leibnitz Zentrum (MLZ), TU München, Lichtenbergstr. 1, 85748, Garching, Germany

c Institute of Materials Research, Helmholtz-Zentrum Geesthacht, Max-Planck-Strasse 1, 21502, Geesthacht, Germany

${ }^{\mathrm{d}}$ VDM Metals International GmbH, Kleffstraße 23, 58762, Altena, Germany

e Institut für Werkstoffe, Technische Universität Braunschweig, 38106, Braunschweig, Germany

\section{A R T I C L E I N F O}

\section{Article history:}

Received 21 May 2019

Received in revised form 12 August 2019

Accepted 3 September 2019

Available online 4 September 2019

\section{Keywords:}

Ni-base superalloys

HRTEM

EELS

STEM

HAADF

\begin{abstract}
A B S T R A C T
VDM 780 Premium is a recently developed Ni-based superalloy designed for working at high service temperatures (above $650^{\circ} \mathrm{C}$ ) while keeping the good workability of alloy 718 . VDM 780 Premium is based on the austenitic matrix ( $\gamma$ phase) strengthened by intermetallic $\mathrm{Ni}_{3} \mathrm{Al}$-like precipitates $(\gamma$ ' phase, fcc $\mathrm{L} 1_{2}$ structure). Other co-precipitates may be formed in function of the applied heat treatment, such as $\mathrm{Ni}_{3} \mathrm{Nb}$-based ( $\delta$ phase, orthorhombic $\mathrm{DO}_{\mathrm{a}}$ structure) or $\mathrm{Ni}_{3}$ Ti-based ( $\eta$ phase, hexagonal $\mathrm{DO}_{24}$ structure) precipitates. The amount as well as the size and morphology of the different precipitates depend on the heat treatments performed on the alloy, playing an important role in improving the creep properties or the behavior during forging and recrystallization. This work contains a complex study using various techniques of analytical electron microscopy and synchrotron diffraction intended to clarify the structure of the high-temperature phase formed in the newly developed VDM 780 Premium alloy. The atomic structure of the high-temperature plate-like precipitates formed in VDM 780 Premium after two different thermal treatments has been investigated in relation with the surrounding matrix lattice, proving the stacked $\delta / \eta$ structure of the precipitates.
\end{abstract}

๑) 2019 Published by Elsevier B.V.

\section{Introduction}

Ni-base superalloys present excellent mechanical properties at high temperatures together with resistance to degradation in corrosive or oxidizing conditions, which makes them suitable for gas turbine engine disc components for land-based power generation and aircraft propulsion [1,2]. Alloy 718 is the most widely used among all Ni-base alloys due to its unique mechanical properties and good processing characteristics [3]. The development of new alloys stable at even higher temperatures, with better and long term performance under operation conditions, is challenging for obtaining higher efficiency turbines including reduced emissions. With the aim to fulfill these requirements, alloy VDM 780 Premium has been recently developed [4,5]. This Ni-base superalloy is based on the $\gamma$ matrix (Ni-based cubic Fm-3m structure) and $\gamma$ ' hardening

\footnotetext{
* Corresponding author.

E-mail address: cecilia.solis@frm2.tum.de (C. Solís).
}

precipitates ( $\mathrm{Ni}_{3} \mathrm{Al}$-based cubic Pm-3m structure). Unlike Alloy 718 , no traces of the $\gamma$ " hardening phase are observed in the newly developed alloy VDM 780 Premium, regardless of the heat treatment. We remind here that the $\gamma$ " phase $\left(\mathrm{Ni}_{3} \mathrm{Nb}\right.$-based, ordered tetragonal DO22 structure, Space Group 139) is unstable above $650^{\circ} \mathrm{C}$, undergoing a phase transition into the $\delta$ phase that causes a loss of Alloy 718 creep resistance. The absence of the $\gamma$ " phase in VDM 780 Premium will prevent the structural instability observed in Alloy 718, creating favorable conditions to increase the range of working temperatures above $650{ }^{\circ} \mathrm{C}$. In addition, other hightemperature phases are also present, whose nature is not yet completely understood. The amount of the corresponding phases as well as the size and morphology of the different precipitates depend on the heat treatments performed on the material [6-8].

The high-temperature phases most likely to occur in such alloys are known as the $\delta$-phase $\left(\mathrm{Ni}_{3} \mathrm{Nb}\right.$ based orthorhombic Pmmn structure) and/or the $\eta$ phase ( $\mathrm{Ni}_{3} \mathrm{Ti}$ hexagonal $\mathrm{P}_{3} / \mathrm{mmc}$ structure). The current discussion regarding the high-temperature precipitates refers, on one side, to their structure ( $\delta$ phase or $\eta$ phase) in relation 
with their composition and, on the other side, to the role played by the two phases in the mechanical properties of the alloy. Depending on the alloy composition, the two phases have been reported to occur either alone or coupled within the same precipitates. Stotter et al. [9] and Viskari et al. [10] analyzed the formation of the $\delta$ phase precipitates in superalloy Allvac 718Plus and Alloy 718. Other authors reported that in Alloy 718Plus the hightemperature precipitates observed at the grain boundaries were not the $\delta$ phase, but their structure was compatible with the $\eta$ phase, although their chemistry was close to $\mathrm{Ni}_{6} \mathrm{AlNb}$ [11] or $\mathrm{Ni}_{6}$ (AlTi)Nb [12]. On the other hand, the presence of the $\eta$ phase in the Alloy 718Plus has been reported also as well-defined singlephase precipitates [13] or as fine layered structures composed of $\delta$ and $\eta$ phases [14].

The role of the high-temperature phases is very important in the possible applications of the final alloy, as they can highly influence the grain size evolution during processing as well as the mechanical properties of the alloy operating at high temperature. Understanding their nature, structure and composition becomes crucial in controlling their formation. As in Nickel Alloy 718, the $\delta$ phase may be used for forming fine grain size during the forging and the recrystallization, hindering the grain growth. However, although the fine-grained structure provides high strength at ambient temperature, grain boundaries become weak areas at elevated temperatures [7]. Furthermore, it has been shown that in some cases of Alloy 718Plus the presence of nanoscale $\eta$ phase precipitates creates a low-energy structure that inhibits the accumulation of stacking faults into twins, leading to a significant improvement of the creep properties [15]. On the other hand, other studies claim that a high amount of the $\eta$ phase is detrimental to the mechanical properties of the alloy [16].

The recently developed alloy VDM 780 Premium has been created with the aim of pushing further the limits of the currently used Nickel alloys by enabling the increase of the operating temperature for high-temperature applications, without losing the good workability of Alloy 718 [4,5]. It turns out that in order to be able to tailor the mechanical properties at high temperatures and to ensure the good performance within the final applications [17-21] of the newly developed alloy VDM 780 Premium, a special attention needs to be given to understanding the nature of the hightemperature phases and their growth mechanism.

We previously reported on the structure of the newly developed alloy VDM 780 Premium by means of neutron diffraction experiments $[6,8]$. However, the structure of the high-temperature phase/ phases present in the material could not be resolved, as it was found to be compatible with both the $\delta$ and $\eta$ phases. Starting from the insufficient relevance of our previous structural studies and considering the controversies encountered in the literature regarding the crystal structure of the high-temperature precipitates in related alloys, this study is focused on the in-depth analysis of the high-temperature phase in the newly developed alloy VDM 780 Premium. Two different samples with the same composition but after two different heat treatments were analyzed. We report on a local structural analysis intended to clarify the structure of the high-temperature phase formed in the newly developed alloy VDM 780 Premium by means of a complex study using various techniques of analytical electron microscopy and synchrotron diffraction.

\section{Experimental}

The composition of the new Ni-based superalloy VDM 780 Premium is given in Table 1. In order to induce the formation of a large amount of high-temperature phase to be analyzed, two different heat treatments were performed as described in Table 2.
Table 1

Chemical composition of the Ni-based superalloy VDM 780 Premium.

\begin{tabular}{lllllllll}
\hline & $\mathrm{Ni}$ & $\mathrm{Co}$ & $\mathrm{Cr}$ & $\mathrm{Fe}$ & $\mathrm{Mo}$ & $\mathrm{Nb}$ & $\mathrm{Al}$ & $\mathrm{Ti}$ \\
\hline wt.\% & balance & 25 & 18 & $<3$ & 3 & 5.4 & 2 & 0.2 \\
\hline
\end{tabular}

The heat treatments were selected for setting up different microstructures. Thus, sample VDM 780-a was produced, containing mainly the $\gamma$ matrix and the high-temperature phase, while sample VDM 780-b shows in addition a large amount of $\gamma^{\prime}$ hardening precipitates [6,7]. In sample VDM 780-a the heat treatment at $1000^{\circ} \mathrm{C}$ ensures the complete dissolution of $\gamma^{\prime}$ phase, while the aim of the step at $975^{\circ} \mathrm{C}$ for $16 \mathrm{~h}$ is to obtain a significant amount of high-temperature phase along the grain boundaries. Considering sample VDM 780-b, the aim of the heat treatment step at $900^{\circ} \mathrm{C}$ for $11 \mathrm{~h}$ is to precipitate a large amount of high-temperature phase along the grain boundaries, thus stabilizing the grain boundaries and preventing grain growth during the following heat treatments. The second step at $955^{\circ} \mathrm{C}$ for $1 \mathrm{~h}$ dissolves already existing $\gamma^{\prime}$ phase while the steps at 800 and $650{ }^{\circ} \mathrm{C}$ are used to precipitate the $\gamma^{\prime}$ phase for strengthening, with no morphological changes of the high-temperature phase. Air cooling produces finer $\gamma^{\prime}$ precipitates which lead to the strength increase, while furnace cooling produces wavier grain boundaries and coarsening of the $\gamma^{\prime}$ precipitates, reducing the hardness and creep rupture strength but increasing ductility [7].

In this work several high-temperature precipitates from two different samples (each one after the described heat treatments) were analyzed. Scanning electron microscopy (SEM) images were taken with a Zeiss LEO 1550 Gemini system. X-ray diffraction (XRD) patterns were obtained with synchrotron radiation at the HEMS beamline at PETRA III at DESY [22] by using a photon energy of $100 \mathrm{keV}$ corresponding to a wavelength of $0.0124 \mathrm{~nm}$. A PerkinElmer XRD1621 image detector with a pixel size of $200 \times 200 \mu \mathrm{m}^{2}$ and a resolution of $2048 \times 2048$ pixels was used to record the XRD patterns. The detector was positioned with a sample-to-detector distance of $1930 \mathrm{~mm}$, such that primary beam hit the detector center, allowing to record complete Debye-Scherrer rings. A $\mathrm{LaB}_{6}$ standard sample (NIST standard reference material SRM-660a) was used for calibration. The 2D patterns from synchrotron measurements were treated with the Fit2D software [23]. Finally, the FullProf package [24] was applied for Rietveld refinement [25] of the acquired synchrotron diffraction patterns. Transmission electron microscopy (TEM) investigations using several techniques were performed on a Cs probe corrected JEM ARM 200F microscope provided with a JEOL energy-dispersive X-ray spectroscopy (EDS) and a Gatan GIF Quantum SE electron energy loss spectroscopy (EELS) analytical units. High-resolution transmission electron microscopy (HRTEM), EDS and EELS investigations were performed in order to determine the nature of the high-temperature phases present on the studied alloy. Scanning transmission electron microscopy (STEM) was combined with the EDS and EELS analytical techniques in order to map the local chemical composition by spectrum imaging (SI). The samples were prepared by mechanical grinding followed by ion milling down to electron transparency using a Gatan PIPS machine.

\section{Results \& discussion}

The surface morphology characterization of the analyzed samples can be observed in the SEM images of Fig. 1 (additional optical microscopy images in Supporting Fig. S1). The image of sample VDM 780-a (Fig. 1a) shows the presence of plate-shaped precipitates with typical length and width of $1-10 \mu \mathrm{m}$ and 
Table 2

Heat treatments $\mathrm{a}$ and $\mathrm{b}$ performed in the alloy VDM 780 Premium, where $\mathrm{FC}=$ furnace cooling, WQ $=$ water quenching and $\mathrm{AC}=\mathrm{air}$ cooling.

\begin{tabular}{lll}
\hline & Sample & Heat treatment \\
\hline a & VDM 780-a & $1000{ }^{\circ} \mathrm{C} / 0.5 \mathrm{~h} / \mathrm{FC} 1 \mathrm{~K} / \mathrm{min}+975{ }^{\circ} \mathrm{C} / 16 \mathrm{~h} / \mathrm{WQ}$ \\
$\mathbf{b}$ & VDM 780-b & $900{ }^{\circ} \mathrm{C} / 11 \mathrm{~h} / \mathrm{AC}+955^{\circ} \mathrm{C} / 1 \mathrm{~h} / \mathrm{FC} 4 \mathrm{~K} / \mathrm{min}+800{ }^{\circ} \mathrm{C} / 8 \mathrm{~h} / \mathrm{FC} 50 \mathrm{~K} / \mathrm{h}+650{ }^{\circ} \mathrm{C} / 8 \mathrm{~h} / \mathrm{AC}$ \\
\hline
\end{tabular}
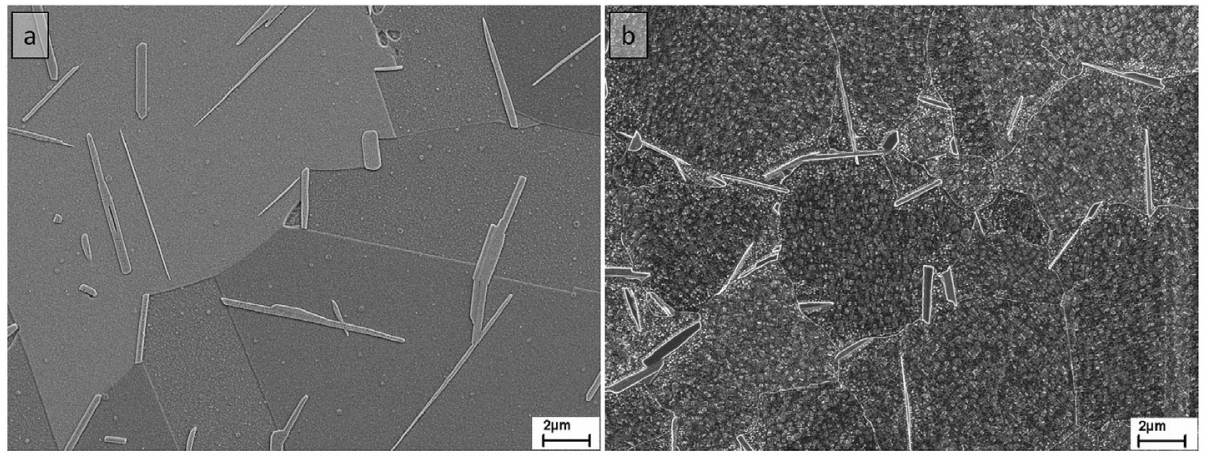

Fig. 1. SEM images of VDM 780 Premium after heat treatments described in Table 2 a) sample VDM 780-a and b) sample VDM 780-b.

$100-500 \mathrm{~nm}$, respectively. These precipitates can be assigned to the high-temperature phase $\delta$ and/or $\eta$. Likewise, Fig. 1b displays the formation of the high-temperature phase along the grain boundaries in sample VDM 780-b, with a size distribution similar to condition a. Furthermore, Fig. 1b exhibits finely distributed $\gamma^{\prime}$ precipitates. These are present in different sizes, according to the complex heat treatment. The following section briefly explains the $\gamma^{\prime}$ precipitation. The purpose of the first step of heat treatment at $900^{\circ} \mathrm{C}$ is the formation of the high-temperature phase. During this process step, $\gamma^{\prime}$ precipitates are formed likewise, both homogeneously inside the grains and occasionally at the grain boundaries. However, $\gamma^{\prime}$ free zones form around the high-temperature phase. The next step is the solution annealing at $955^{\circ} \mathrm{C}$, meant to essentially dissolve the $\gamma^{\prime}$ phase, even though a small amount still persists. This small amount of $\gamma^{\prime}$ phase can continue to grow during the additional furnace cooling process. These coarser $\gamma^{\prime}$ precipitates are clearly visible in Fig. 1b, leading to additionally serrated grain boundaries. During precipitation hardening at $800^{\circ} \mathrm{C}$, the slightly smaller $\gamma^{\prime}$ precipitates form in the formerly $\gamma^{\prime}$ free zones around the high-temperature phase. The precipitate particles that form during the last step at $650^{\circ} \mathrm{C}$ are only a few nm in size and not resolvable with the SEM [6-8]. Further information regarding the $\gamma^{\prime}$ precipitation in the VDM 780 Premium alloy can be found in Ref. [7].

The Rietveld refinements of the synchrotron diffraction patterns measured at the P07-HEMS [22] instrument at PETRA III (DESY) for samples VDM 780-a and VDM 780-b are presented in Fig. 2. The red open circles show the measured data, while the black line represents the calculated data obtained from Rietveld refinement. The lower blue line represents the difference between the experimental and calculated data sets. The graphs also show the theoretical Bragg peak positions for the $\gamma, \gamma^{\prime}$ (only in sample VDM 780-b), $\eta$ and $\delta$ phases (green markers from up to bottom). The diffraction pattern analysis proves that both samples contain the $\gamma$ phase (the matrix) together with both $\delta$ and $\eta$ high-temperature phases, as well as some traces of NbC. In addition, the VDM-780-b sample also shows the $\gamma^{\prime}$ hardening phase $[6,12,26]$. The unambiguous presence of both high-temperature phases is confirmed by the presence of the following reflections: $\delta(201)(002)$ at $3.2^{\circ}, \eta(202)$ at $4.09^{\circ}, \delta(220)$ at $4.37^{\circ}, \eta(210)$ at $4.95^{\circ}, \delta(013)$ at $5.10^{\circ}$, etc (the complete list of the observed reflections and assigned phases can be found in Supporting information Table S1).
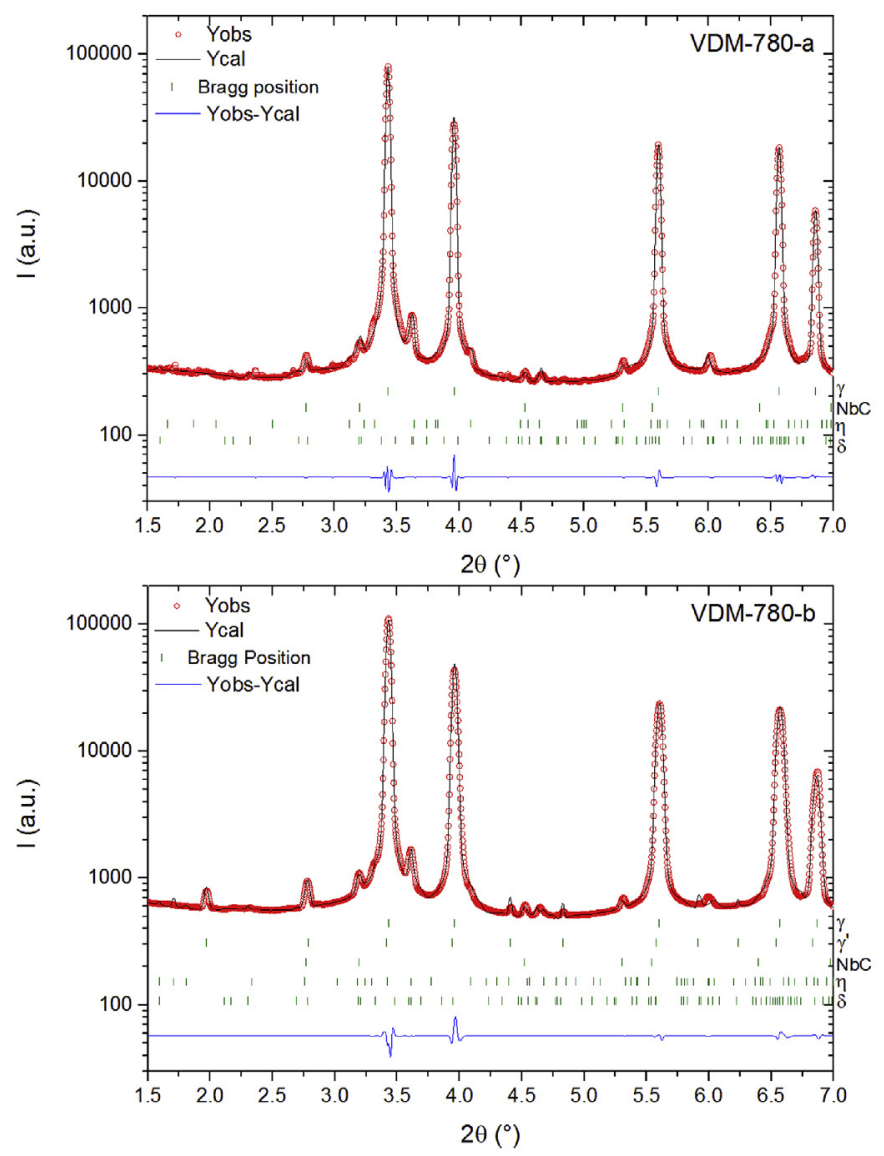

Fig. 2. The Rietveld refinement pattern (red circles: observed data and black line: calculated data) and difference plot (blue line) of the synchrotron data for the superalloy VDM 780-a and 780-b. The markers indicate the Bragg peak positions of the $\gamma$ matrix, $\gamma^{\prime}$ phase, $\mathrm{NbC}$, and the $\eta$ and $\delta$ high-temperature phases (from top to bottom). (For interpretation of the references to color in this figure legend, the reader is referred to the Web version of this article.)

For investigations at higher space resolution meant to identify and properly characterize the atomic structure and composition of 
the high-temperature precipitates containing the $\delta$ and/or $\eta$ phases, we combined several techniques of analytical TEM to be presented hereafter.

As a general characteristic, the sample VDM 780-a presents a high density of dislocations and a low density of precipitates. A typical edge-on plate-shaped precipitate is presented in dark diffraction contrast in Fig. 3a, with a length of ca. $2 \mu \mathrm{m}$ and a width of $0.3 \mu \mathrm{m}$. The sample was tilted to the nearest zone axis orientation and the corresponding diffraction pattern recorded from an area selected inside the precipitate is presented in Fig. 3b. In a first approximation, the diffraction pattern can be indexed according to the hexagonal crystal structure of the $\eta$ phase. The main Miller indices of the $\eta$ phase are indicated on the figure. Thus, the hexagonal $c$ axis of the $\eta$ phase is oriented perpendicular to the plateshaped precipitate which is oriented edge-on along the $[010]_{\eta}$ zone axis. The appearance of the $001_{\eta}$ spot in the diffraction pattern of the hexagonal $\eta$ phase is most likely due to the ordering of $\mathrm{Al}$ and $\mathrm{Nb}$ as described by Pickering et al. [11].

A close inspection of the diffraction patterns reveals two significant features:

i. The occurrence of intensity streaks between the diffraction spots, parallel to the $(001)_{\eta}$ reciprocal vector: the inset in the upper right corner of the micrograph (Fig. 3b) is a zoomed-in area from the central part of the diffraction patterns featuring faint intensity streaks between the diffraction spots; ii. The splitting of the high-index diffraction spots: the inset in the bottom right corner of the diffraction patterns (Fig. $3 \mathrm{~b}$ ) reveals the splitting of the $\left(\begin{array}{llll}0 & 0 & 12\end{array}\right)_{\eta}$ spot.

These observations are consistent with the presence of a high density of planar defects parallel to the hexagonal plane of the $\eta$ phase and, respectively, with the presence of a second crystal phase of close lattice parameters (in the considered orientation). The TEM images at higher magnifications (Fig. $3 c$ and d) show that, indeed, the precipitate contains planar defects oriented parallel to its long sides. Moreover, the precipitate has a band-like structure consisting in ribbons of different contrast with a variable width, which most probably correspond to two different crystal structures, as suggested by the splitting of the high-index diffraction spots (Fig. 3b). Consequently, the diffraction pattern can be indexed as the overlap of two phases corresponding to the alternating domains, having close values of the lattice parameters in this particular crystal orientation: the orthorhombic $\delta$ and the hexagonal $\eta$ phases. The analyzed diffraction pattern includes also the Miller indices associated to the $\delta$ phase domains. Thus, the $\delta$ domains are imaged in the $[100]_{\delta}$ zone axis orientation, while the crystallographic relationship with the adjacent $\eta$ domains is described by $[010]_{\eta} \|$ $[100]_{\delta},(001)_{\eta}\left\|(010)_{\delta},(100)_{\eta}\right\|(001)_{\delta}$. The relevant interplanar distances $d_{h k l}$ associated to the diffraction spots in the analyzed diffraction patterns have, indeed, very closed values [6]: $\mathrm{d}_{002 \eta}=0.417 \mathrm{~nm}, \mathrm{~d}_{010 \delta}=0.425 \mathrm{~nm}$, i.e. $1.9 \%$ mismatch, and,

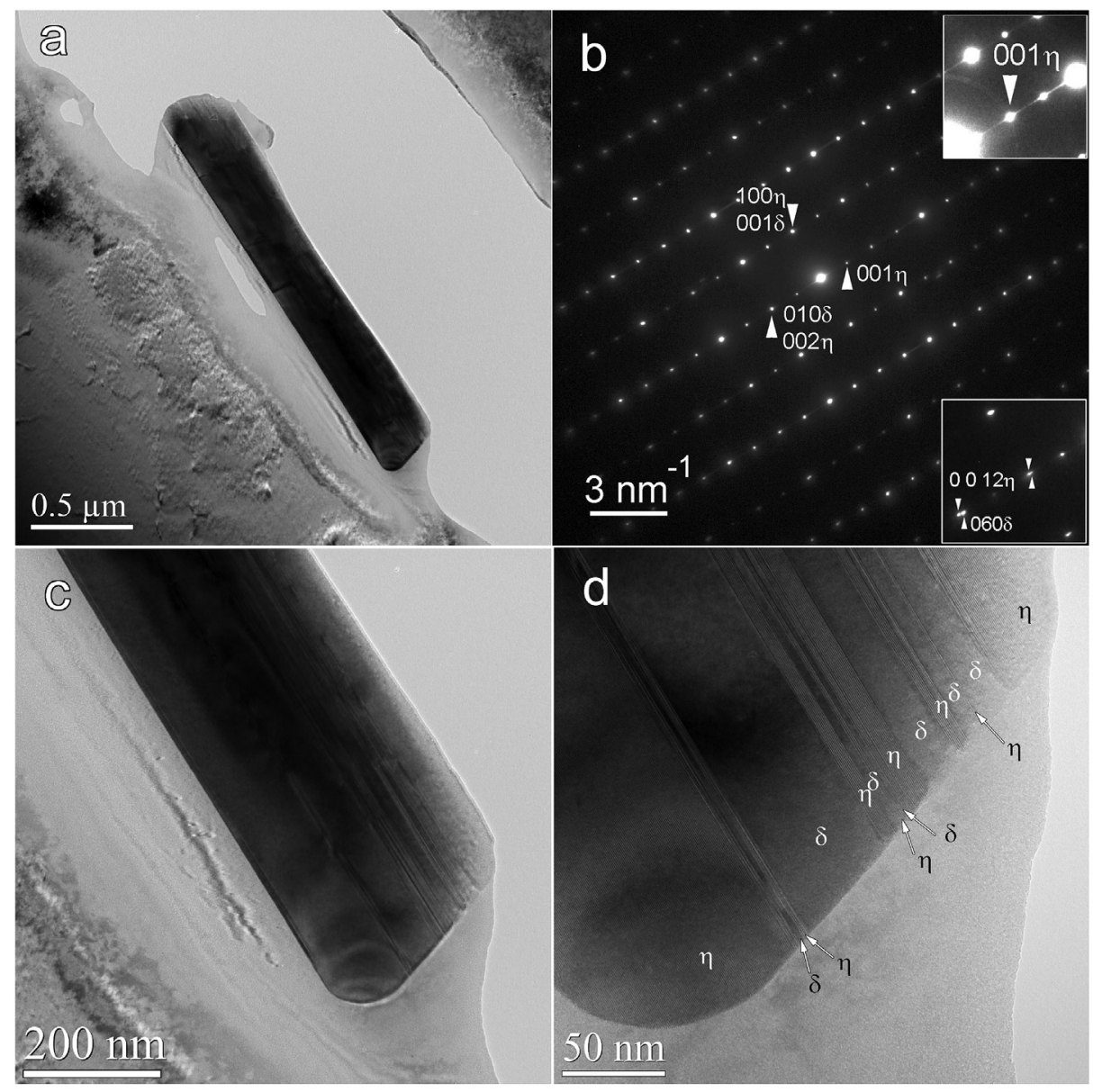

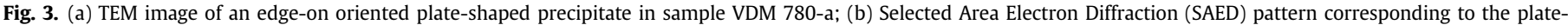

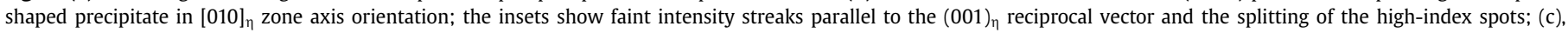
(d) TEM images at higher magnification revealing the presence of planar defects separating band-like domains inside the precipitate. 
respectively, $\quad d_{100 \eta}=0.443 \mathrm{~nm}, \quad \mathrm{~d}_{001 \delta}=0.455 \mathrm{~nm}, \quad$ i.e. $\quad 2.7 \%$ mismatch.

The atomic structure of the plate-shaped precipitate in the sample VDM 780-a can be observed in the HRTEM images in Fig. 4a and $b$. The precipitate consists of band-like structural domains showing two different types of HRTEM patterns, marked with 1 and 2 on the micrographs. The fast Fourier transform (FFT) patterns shown in Fig. 4c and d were obtained by selecting areas inside each type of structural domains. This way it is possible to distinguish the two structural domains, unlike the selected-area electron diffraction (SAED) patterns where the selecting aperture included areas from both types of domains, resulting into a composed diffraction pattern containing information from the two different structures. The FFT patterns of the two types of domains prove that, indeed, they have two distinct crystal structures, corresponding to the two high-temperature phases, $\delta$ and $\eta$.

The SAED pattern and HRTEM micrograph in Figs. 3 and 4 represent only a $2 \mathrm{D}$ projection of the crystalline system formed by the two adjacent phases inside the plate-like precipitate, in the reciprocal space and the real space, respectively. For a better visualization of the crystallographic relationship between the two phases we used the VESTA ${ }^{\mathrm{TM}}$ software to generate a 3D structural model of the $\delta-\eta$ system. In Fig. 5 we present the structural model obtained by joining together two crystal grains of $\delta$ and $\eta$ phases oriented to each other according to the crystallographic relationship deduced from the SAED/FFT analysis. The structural model is presented both as a 3D rendering and in 3 different projections, along the main axes of the $\delta$ phase structure: $\mathbf{b}_{\delta} \| \mathbf{c}_{\eta}, \mathbf{c}_{\delta}$ and $\mathbf{a}_{\delta}$ axes, the latter corresponding to the orientation in the analyzed SAED pattern and HRTEM micrograph. We emphasize that the exhibited structural model is only a simple one, meant to offer an idea about the crystallographic orientation between the $\delta$ and $\eta$ phases inside the plate-like precipitate, starting from the SAED and HRTEM observations. A detailed structural description of the phase boundary is rather difficult, considering that the two adjacent phases, $\delta$ and $\eta$, have different structures, orthorhombic and hexagonal, respectively, with incommensurable lattice parameters. However, although the analyzed phase boundary cannot correspond to a perfect coincidence site lattice, the local 2D symmetry of the crystallographic planes in the two phases coming into contact in the given relative orientation suggests a low-energy situation characterized by a high density of coincidence sites, with the contribution of some elastic stress. The analyzed $\delta-\eta$ phase boundary corresponds to the $(010)_{\delta}$ lattice plane of the orthorhombic $\delta$ phase being in contact with the hexagonal basal plane $(001)_{\eta}$ of the $\eta$ phase. The distance between two adjacent lattice sites in the hexagonal basal plane measures $0.254 \mathrm{~nm}$. The local symmetry around the $\mathrm{Nb}$ position in the $(010)_{\delta}$ plane is quasi 6 -fold type, with distances of $0.256 \mathrm{~nm}, 0.260 \mathrm{~nm}, 0.263 \mathrm{~nm}$ to the adjacent $\mathrm{Ni}$ atoms and angles of $58.2^{\circ}, 60.9^{\circ}, 60.6^{\circ}$ formed by the adjacent $\mathrm{Ni}-\mathrm{Nb}-\mathrm{Ni}$ coplanar sites. This corresponds to a mismatch varying between 0.7 and $3.5 \%$ with respect to the coplanar
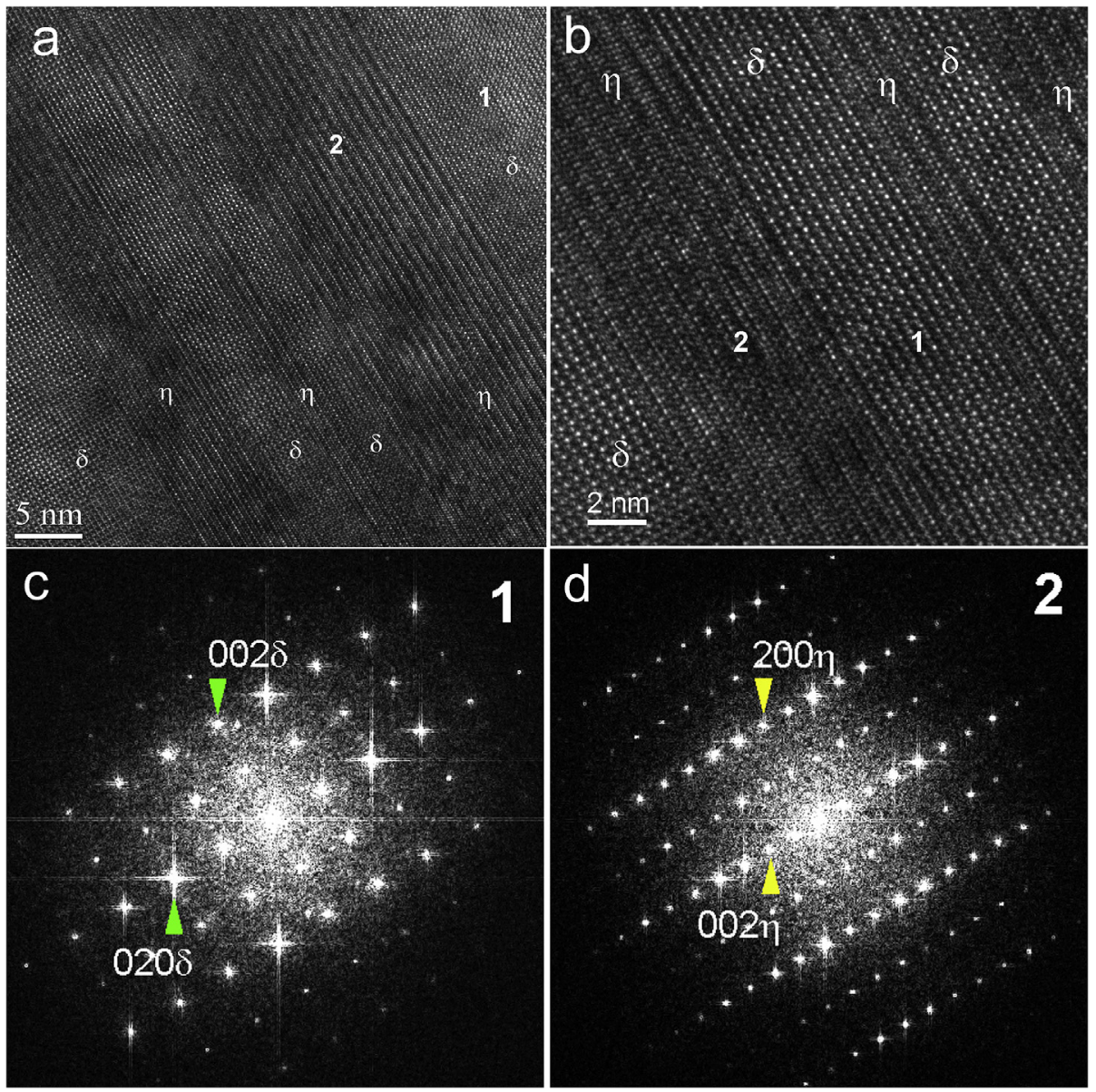

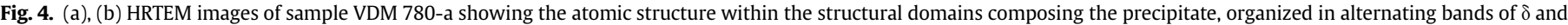

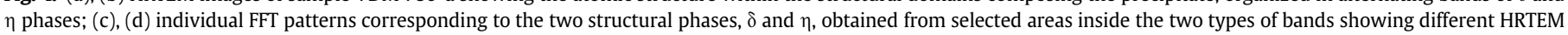
patterns. 

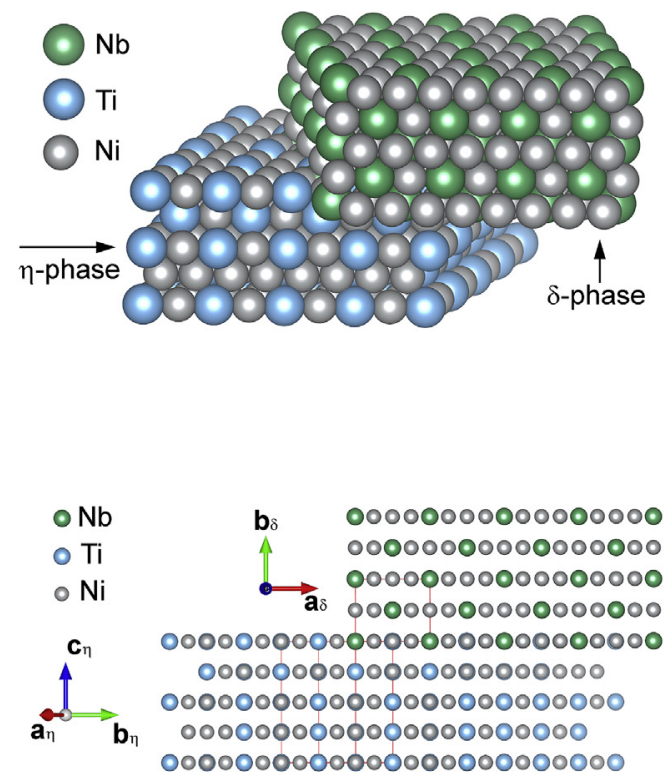
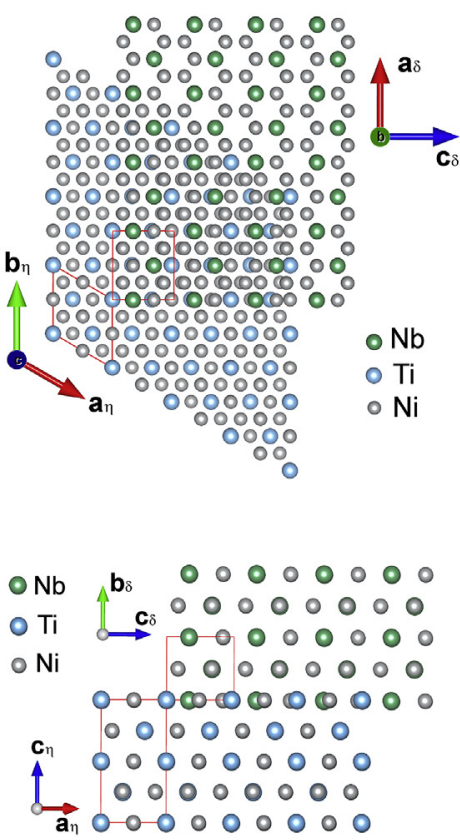

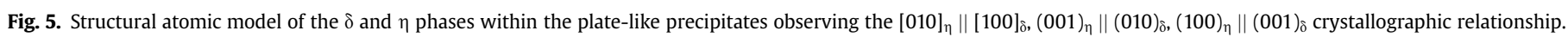
$3 \mathrm{D}$ rendering and projections along the main axes of the $\delta$ phase.
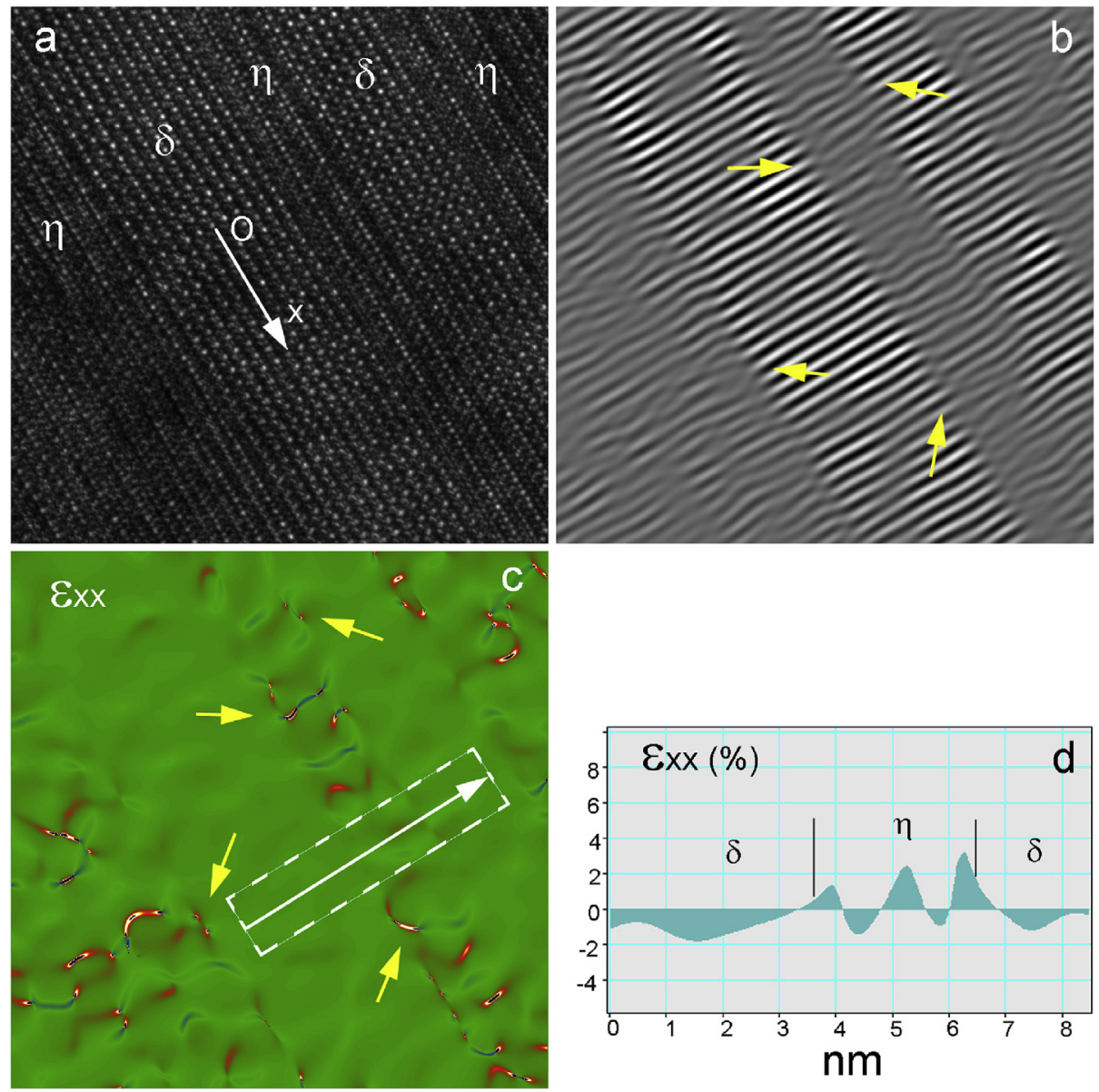

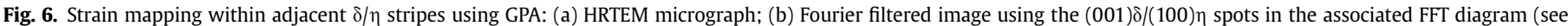

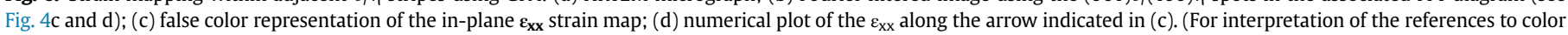
in this figure legend, the reader is referred to the Web version of this article.) 

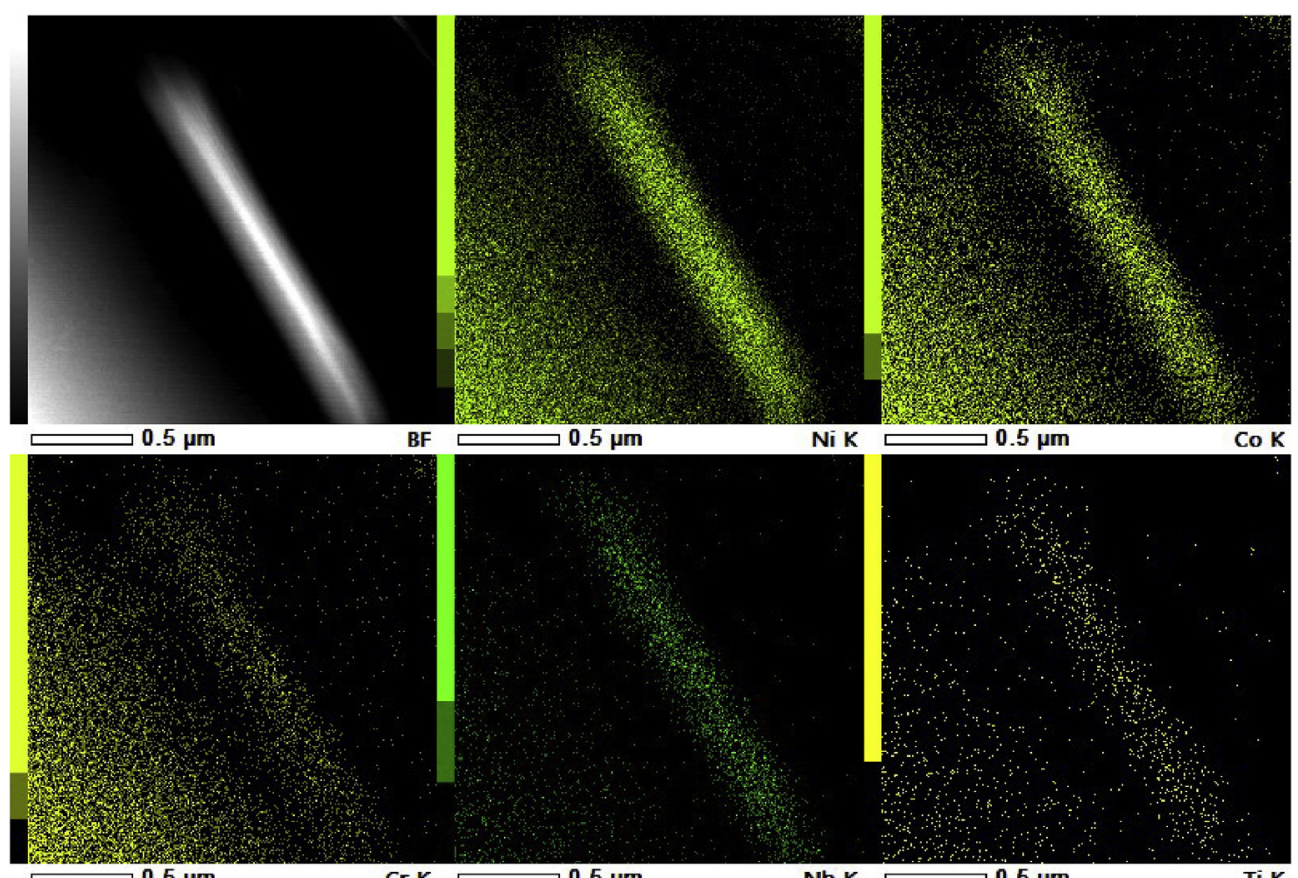

$0.5 \mathrm{\mu m}$
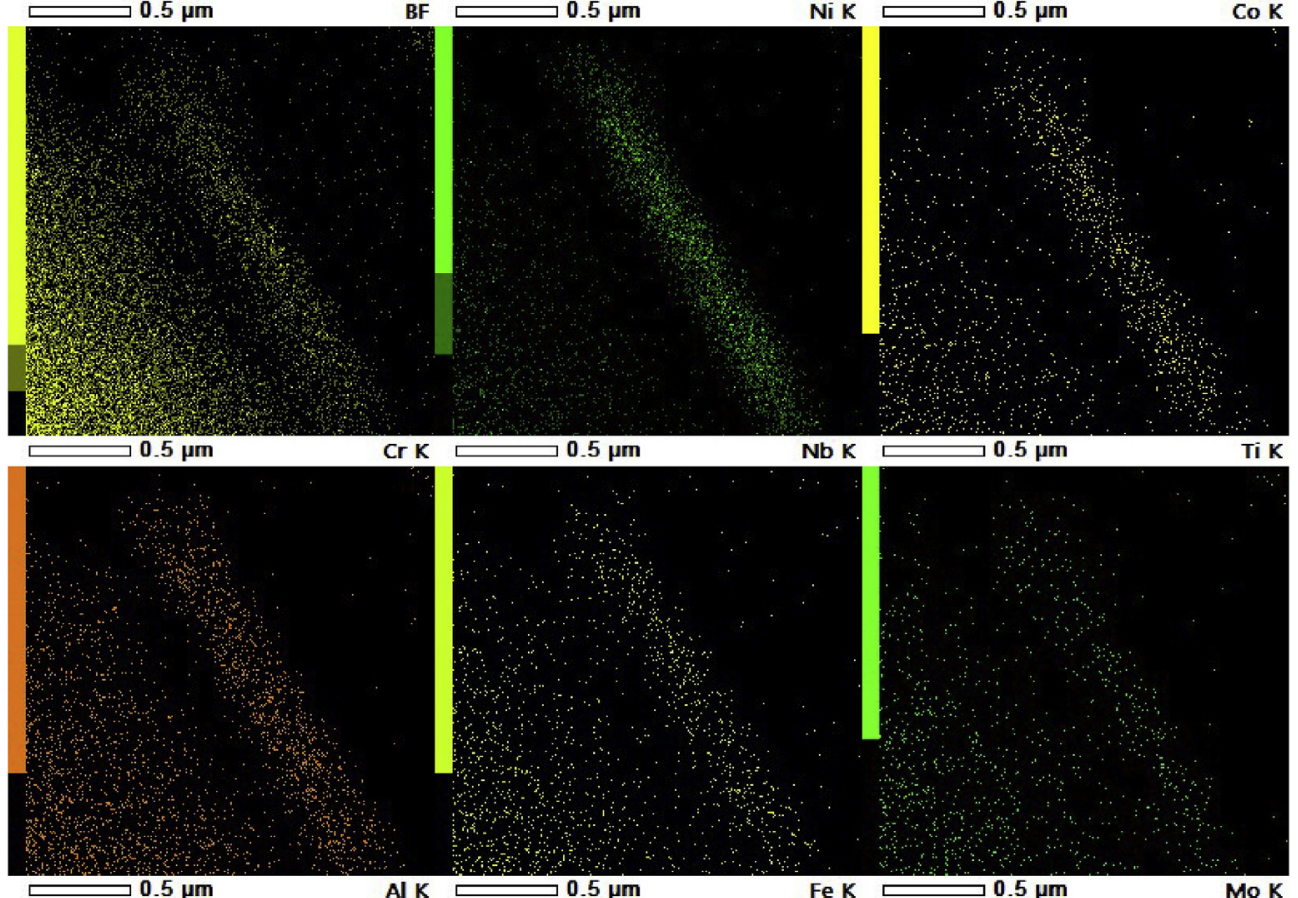

Fig. 7. STEM-HAADF image and EDS compositional maps of the elements identified in the sample VDM 780-a.

interatomic distances in the hexagonal basal plane of the $\eta$ phase. This mismatch can be compensated by the accumulation of elastic stress in the system, allowing for a compact stacking of the atoms from the $\delta$ and $\eta$ phases across the phase boundary (like the a-b planes in a hexagonal compact stacking) and a coherent growth of adjacent $\delta-\eta$ slabs in the described orientation.

Geometrical Phase Analysis (GPA) was used to analyze the strain field around the $\delta-\eta$ interfaces within the plate-like precipitate $[27,28]$. The HRTEM micrograph in Fig. 6a contains several adjacent $\delta-\eta$ stripes within a plate-like precipitate. For the GPA mapping of the strain field we considered a reference area inside the central $\delta$ phase stripe where we marked also the chosen reference Ox direction. The chosen reference was used to calculate the reference reciprocal space vectors and the local variation of the interplanar distance (the strain field) around the structural defects. The inplane strain field $\varepsilon_{\mathrm{xx}}$ was calculated as the derivative of the local displacement field with respect to the Ox direction chosen parallel to the $\delta-\eta$ interface (not shown here). The Bragg-filtered image in Fig. $6 \mathrm{~b}$ was obtained by filtering out all the spatial frequencies but those corresponding to the $(001)_{\delta} /(100)_{\eta}$ spots in the associated FFT diagram. The filtered image shows the degree of lattice coherence across the interface, revealing the presence of dislocations as half-planes starting from the interface (yellow arrows in Fig. 6b). The $\varepsilon_{\mathrm{xx}}$ strain map shows a rather uniform coloring except for some well-defined locations (marked by yellow arrows) where the strain accumulation around the dislocations cores may be noticed. The dislocations are generated at the $\delta-\eta$ interfaces and within the $\eta$ phase stripes, while no dislocations are observed inside the $\delta$ domains. The numerical values of the local strain are plotted in Fig. 6d where the graph corresponds to the line profile across the $\delta-\eta$ interface averaged on the width of the dashed rectangle. The oscillating tensile-compressive character of the

Table 3

Elemental composition measured on EDS spectra extracted out of the data cube from different areas inside and around the precipitate in Fig. 7 .

\begin{tabular}{|c|c|c|c|c|c|c|c|c|}
\hline Area & $\mathrm{Al} \mathrm{K}$ (at \%) & Ti K (at \%) & Cr K (at \%) & Fe K (at \%) & Co K (at \%) & Ni K (at \%) & $\mathrm{Nb} \mathrm{K}$ (at \%) & Mo K (at \%) \\
\hline Matrix & 3.3 & 0.3 & 20.2 & 0.9 & 24.3 & 46.9 & 2.6 & 1.6 \\
\hline Precipitate-central part ( $\delta$ and $\eta$ phases mixed) & 2.4 & 0.8 & 4.9 & 0.2 & 20.2 & 56.8 & 14.5 & 0.1 \\
\hline Precipitate - left side ( $\eta$-phase dominant) & 3.7 & 0.4 & 5.6 & 0.2 & 19.5 & 62.4 & 8.2 & - \\
\hline
\end{tabular}


strain field inside the $\eta$ phase stripe is due to the presence of the dislocations formed at the interface and also inside the $\eta$ domains as a stress relaxation mechanism.

The chemical composition of the precipitate was investigated by EDS and EELS in STEM mode. Spectral images from areas including the precipitate were acquired both in EDS and EELS modes. For the EDS elemental mapping the following acquisition parameters were used: spot size $0.15 \mathrm{~nm}$ ( $5 \mathrm{C}$ according to the instrument notation), condenser aperture $40 \mu \mathrm{m}$, probe current $240 \mathrm{pA}$, camera length $8 \mathrm{~cm}$, map resolution $256 \times 256$ pixels, dwell time $0.1 \mathrm{~ms}$. The STEM-EDS elemental maps of sample VDM 780-a shown in Fig. 7 indicate a relative $\mathrm{Nb}$ enrichment to the detriment of $\mathrm{Cr}$ inside the precipitate with respect to the matrix (see also Supporting Fig. S4). As the sample thickness is not uniform around the precipitate (non-uniform sputtering during the ion milling process), the visual interpretation of the elemental maps becomes more difficult. Considering the contrast in the STEM image obtained with a high-angle annular dark field (HAADF) detector, the matrix thickness in the close vicinity of the precipitate is significantly thinner. The precipitate itself exhibits a non-uniform thickness, being thicker in the central part than the lateral borders or the upper and bottom ends. For a comparative quantitative analysis, several EDS spectra were extracted out of the STEM-EDS data cube: from the central part of the precipitate, the left side of the precipitate and the surrounding matrix. We mention that, according to the HRTEM observation, on the left side of the precipitate only the $\eta$ phase is present (Fig. 3d), while in the central part a layered structure was noticed consisting in alternating $\delta$ and $\eta$ bands.

Comparing the quantitative data resulting from the extracted local EDS spectra (Table 3), an increase of the $\mathrm{Nb}$ and Ni concentration and a deficit of $\mathrm{Cr}$ is measured inside the precipitate with respect to the matrix. A local variation of the chemical composition can be observed also inside the precipitate. The central part, where alternating $\delta$ and $\eta$ stripes were revealed by HRTEM, shows a higher concentration of $\mathrm{Nb}$ as compared to the left border of the precipitate where a wide band of $\eta$ phase was identified by HRTEM. Thus, the corroborated HRTEM and EDS results point out a certain compositional variation between the $\delta$ and $\eta$ phases. However, the lateral resolution of the EDS elemental maps is rather limited due to lateral electron scattering, not allowing us to clearly evidence this compositional difference. Therefore, the same precipitate was further analyzed by EELS spectrum imaging. A spectral image was acquired from the area $(137 \times 29$ pixels, $3.4 \mathrm{~nm} /$ pixel $)$ marked on the STEM-HAADF micrograph in Fig. 8. We used the following acquisition conditions: spot size $0.12 \mathrm{~nm}$ (spot size $7 \mathrm{C}$ according to the instrument notation), condenser aperture $40 \mu \mathrm{m}$, probe current $75 \mathrm{pA}$, camera length $3 \mathrm{~cm}$, spectrometer entrance aperture $5 \mathrm{~mm}$, spectral resolution $1 \mathrm{eV}$, spectral dispersion $0.5 \mathrm{eV} /$ channel, pixel time $0.1 \mathrm{~s}$. Two EEL spectra were extracted from the EELS-SI data cube (Fig. $8 \mathrm{~b}$ and c), corresponding to the $170-500 \mathrm{eV}$ and 300-1100 eV spectral ranges, where the absorption edges of $\mathrm{Nb}$ $\left(\mathrm{M}_{4,5}\right.$ at $\left.205 \mathrm{eV}\right), \mathrm{Ti}\left(\mathrm{L}_{3,2}\right.$ at $\left.456 \mathrm{eV}\right), \mathrm{Cr}\left(\mathrm{L}_{3,2}\right.$ at $\left.575 \mathrm{eV}\right)$, Co $\left(\mathrm{L}_{3,2}\right.$ at $779 \mathrm{eV})$ and $\mathrm{Ni}\left(\mathrm{L}_{3,2}\right.$ at $\left.855 \mathrm{eV}\right)$ were identified. The elemental maps showing the local intensity of the EELS signal associated to the mentioned absorption edges are presented next to the STEM image. Among all the elemental maps, the Nb distribution shows a local signal variation, with maxima that are correlated with the increase of the scattered electrons intensity in the dark-field (DF) STEM image as well as with the presence of the $\delta$ phase structural domains. It is thus confirmed that the higher $\mathrm{Nb}$ content corresponds to the formation of the $\delta$ phase. Along with the diffraction and highresolution imaging techniques, the local analytical investigations by EDS and especially by EELS confirm that the high-temperature plate-like precipitates in the sample VDM 780-a contain two interleaved structural phases, showing clear compositional variations with respect to each other and to the host lattice.

Similar investigations were performed on sample VDM 780-b which, besides the matrix and the high-temperature phases, contains also the $\gamma^{\prime}$ hardening phase. Fig. 9 shows the typical TEM image of a high-temperature precipitate in sample VDM 780-b. The TEM images in Fig. 9a and b exhibit a fragment of an edge-on oriented plate-shaped precipitate about $3.5 \mu \mathrm{m}$ long and $75 \mathrm{~nm}$ wide at the border between several host lattice crystal grains. The precipitate is oriented along the nearest available zone axis and SAED patterns were recorded from areas belonging to both the lattice and the precipitate, in the same conditions of specimen tilt. The diffraction pattern in Fig. 9c corresponds to the host lattice crystal grain in dark contrast surrounding the plate-shaped precipitate. At a careful inspection, faint diffraction spots can be observed in the hhl positions, with $h$ and $l$ odd (marked by the tilted red arrowhead in Fig. 9c). These spots, while extinguished in the case of the fcc
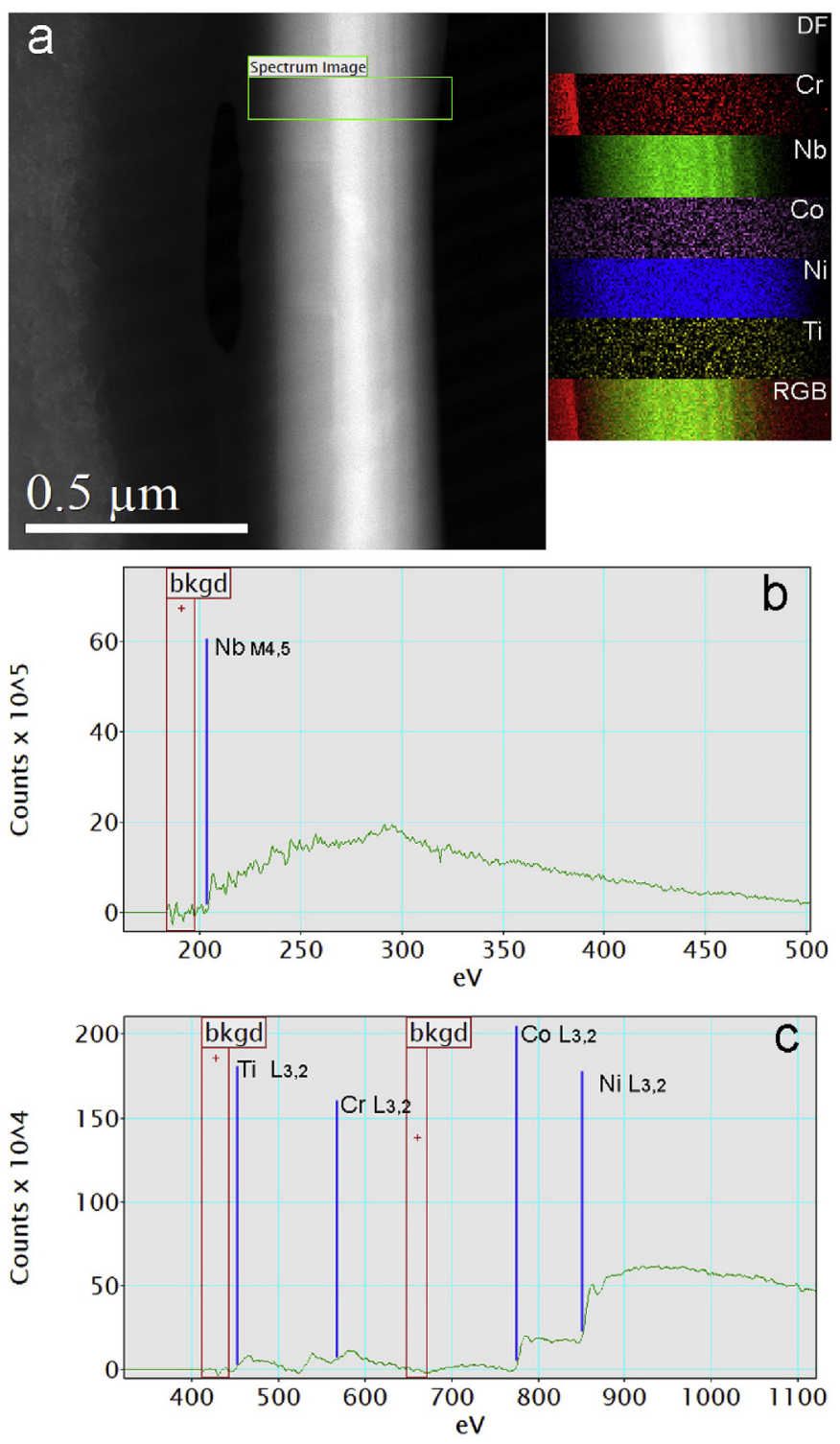

Fig. 8. (a) STEM-HAADF image pointing the area from which the EELS-SI was acquired; the DF image, the elemental maps and the composite image in false colors are presented next to it; (b), (c) EEL spectra extracted from the whole SI area showing the Nb $\mathrm{M}_{4,5}, \mathrm{Ti} \mathrm{L}_{3,2}, \mathrm{Cr} \mathrm{L}_{3,2}$, Co $\mathrm{L}_{3,2}$ and $\mathrm{Ni}_{3,2}$ absorption edge used for elemental mapping. (For interpretation of the references to color in this figure legend, the reader is referred to the Web version of this article.) 
structure characteristic to the $\gamma$ phase, indicate a local modification of the structure factor (which becomes different from zero) caused by compositional variation. They appear consistently inside NbAlrich square-like precipitates evidenced by STEM-EDS mapping (see supporting Figs. S2 and S3). Therefore, this diffraction pattern perfectly fits the $\mathbf{B}_{\gamma^{\prime}}=[1-10]$ zone axis orientation of the $\gamma^{\prime}$ phase.

The plate-shaped precipitate is structurally coherent with the host lattice, showing a well-defined crystallographic orientation with respect to it, as revealed by the diffraction pattern obtained in the same specimen tilt condition. The SAED pattern in Fig. 9d corresponds to a selected area including both the precipitate and the host lattice. Therefore, this diffraction pattern is actually the overlap between the precipitate and the adjacent lattice (identified as $\gamma^{\prime}$ ) diffraction patterns. The precipitate diffraction pattern can be indexed according to the orthorhombic structure of $\mathrm{Ni}_{3} \mathrm{Nb}$ (the $\delta$ phase) along the $\mathbf{B}_{\delta}=[100]$ zone axis. The Miller indices in Fig. 9d refer to the $\delta$ phase orthorhombic structure (green arrowheads). The spots belonging to the adjacent lattice are indicated by redcolored tilted arrowheads. The crystallographic relationship between the adjacent crystal grain and the analyzed plate-shaped precipitate is: $[100]_{\delta}\left\|[1-10]_{\gamma^{\prime}},(010)_{\delta}\right\|(-1-11)_{\gamma^{\prime}}$. At a close inspection of the diffraction pattern in Fig. 9d, one can notice diffuse intensity streaks accompanying the precipitate diffraction spots (see the inset in Fig. 9d), running parallel to the $(010)_{\delta}$ reciprocal vector, suggesting a high density of (010) planar defects inside the precipitate. These planar defects may indeed be observed in Fig. 9b as relatively darker lines along the precipitate, running parallel to its lateral borders. Another important feature is the presence of diffraction spots in fractional positions $1 / 20 \mathrm{kl}$, with $\mathrm{k}$ odd, as pointed by the yellow vertical arrowheads in Fig. 9d. As these spots cannot be explained by the orthorhombic $\delta$ phase, their origin will be approached hereafter by analyzing the corresponding HRTEM micrographs.

At higher magnification (Fig. 10a and b), as the atomic structure becomes visible in the HRTEM mode, one can clearly notice that the precipitate is organized in structural domains in the form of bands running parallel to the long side of the precipitate. Two different HRTEM patterns can be observed inside the precipitate, corresponding to the structural bands noted with 1 and 2 in Fig. 10. The FFT patterns from areas selected inside the two structural bands are presented in Fig. 10d. The FFT pattern of area 1 was indexed according to the crystal structure of the orthorhombic $\delta$ phase. The FFT pattern of area 2 contains an additional set of spots located in the fractional positions $1 / 20 \mathrm{kl}$ positions, $\mathrm{k}$ odd, when indexed according to the $\delta$ phase crystal structure. The explanation for the presence of these spots in fractional positions comes from the existence of a second crystalline phase corresponding to area 2 inside the plate-shaped precipitate, namely the hexagonal $\eta$ phase
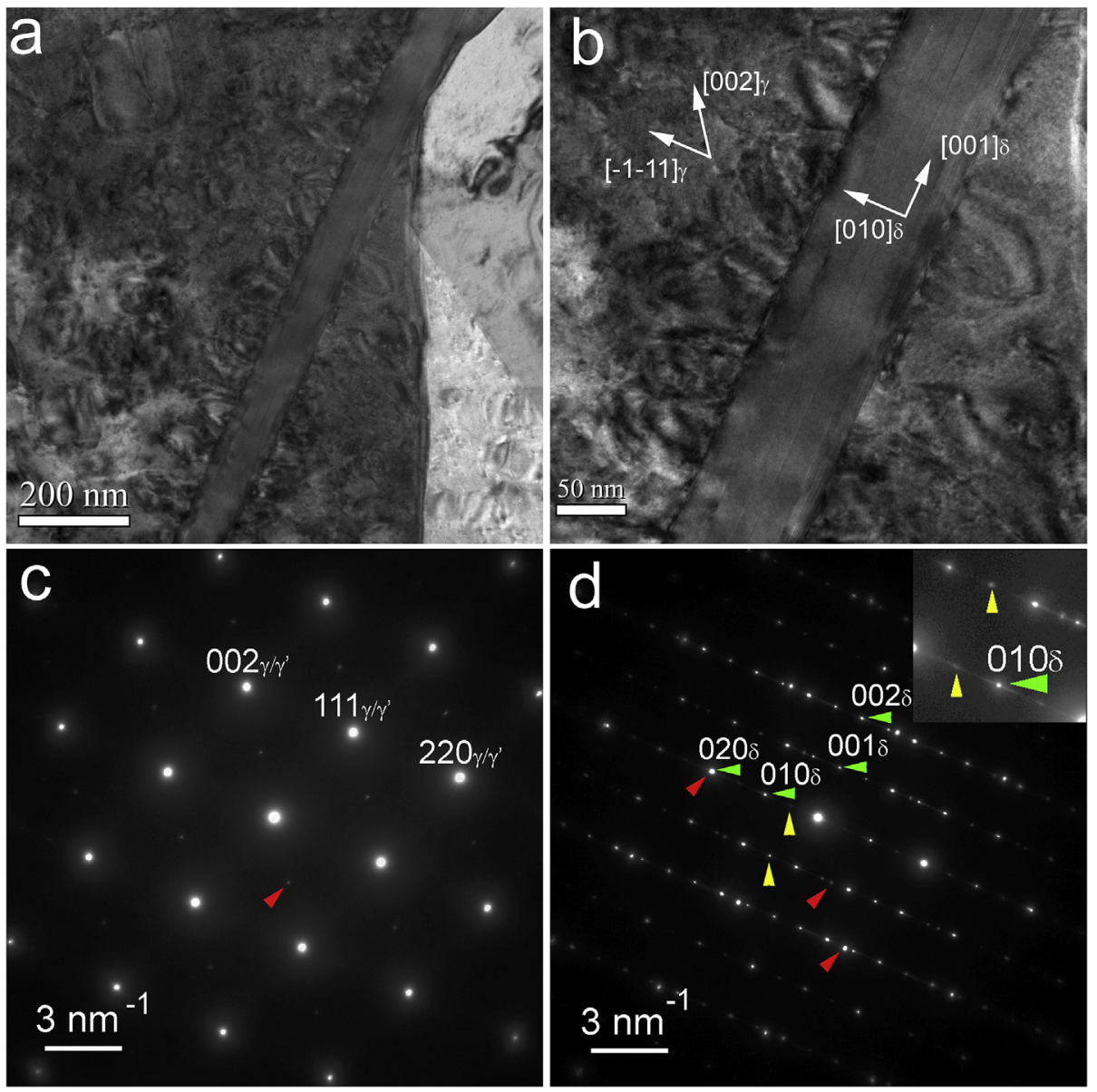

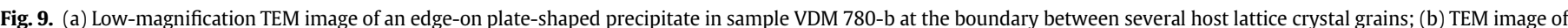

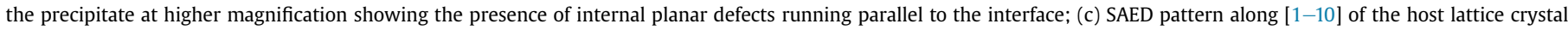

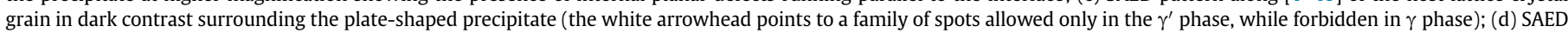

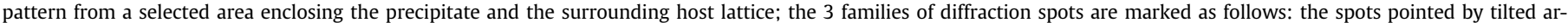

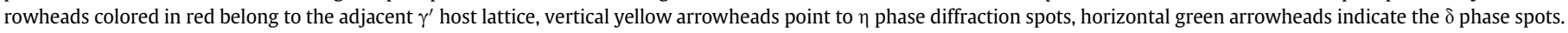
(For interpretation of the references to color in this figure legend, the reader is referred to the Web version of this article.) 
specific to $\mathrm{Ni}_{3} \mathrm{Ti}$-based compositions.

The FFT of area 2 in Fig. 10 was indexed according to the hexagonal structure of the $\eta$ phase, resulting into the $\mathbf{B}=[010]_{\eta}$ zone axis orientation of the $\eta$ phase precipitate in this micrograph.

The strain field at the interface between the two hightemperature phases was analyzed using the same GPA routine (Fig. 10e and f). The in-plane strain map $\varepsilon_{\mathrm{xx}}$ in Fig. 10e reveals the presence of dislocations at the $\delta$ - $\eta$ interface and inside the $\delta$ phase stripe as a mechanism for the partial relief of the lattice mismatch.
We remind here that the nominal lattice mismatch between the $(001)_{\delta}$ planes (interplanar distance $\left.0.455 \mathrm{~nm}\right)$ and $(100)_{\eta}$ planes (interplanar distance $0.443 \mathrm{~nm}$ ) coming in contact at the $\delta-\eta$ interface is $2.7 \%$, while the strain value determined by GPA indicates a relative strain of less than $1 \%$ of the $\delta$ phase stripe with respect to the $\eta$-phase taken as reference, while the remaining $1.7 \%$ of lattice mismatch is compensated by elastic stress.

By corroborating the results of the combined SAED-HRTEM-FFT analysis, we demonstrated that the SAED pattern in Fig. 9d
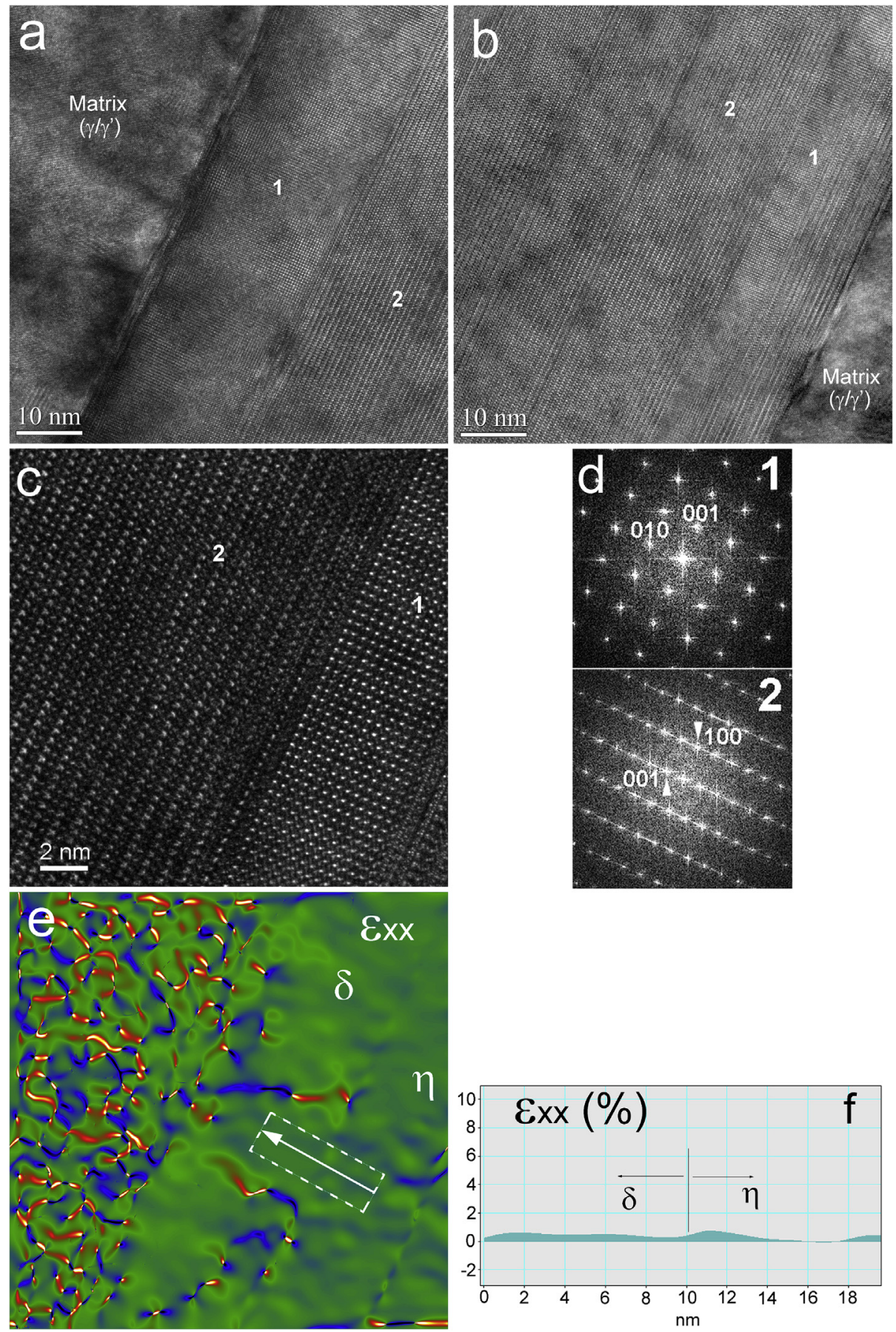

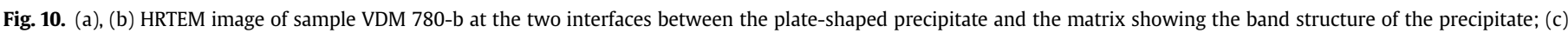

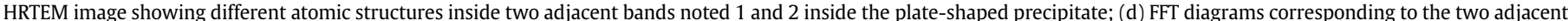

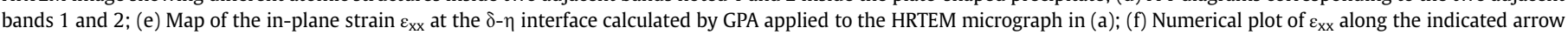
across the $\delta-\eta$ interface. 


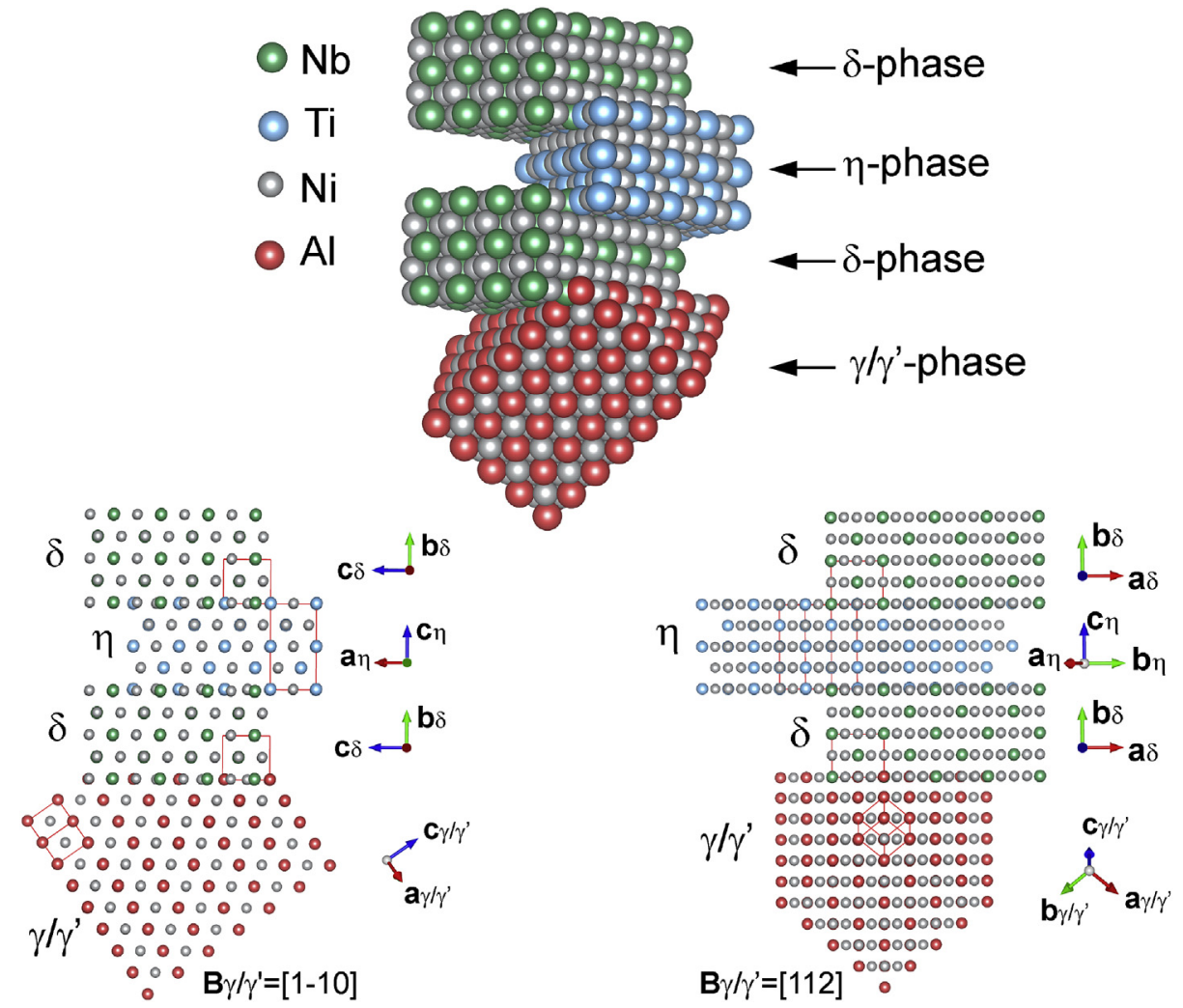

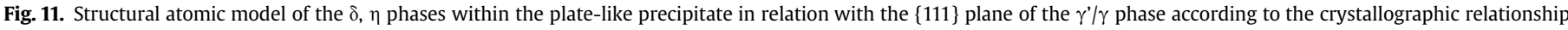

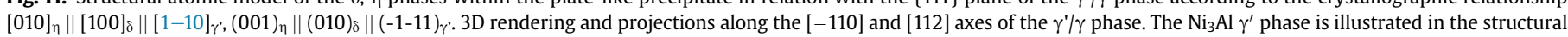
model.

represents actually the overlap of 3 diffraction patterns from 3 different crystal phases: the $\gamma^{\prime}$ phase grain adjacent to the plate- like precipitate, $\delta$ and $\eta$ phases inside the plate-like precipitate. Like in the previous sample, the crystallographic relationship
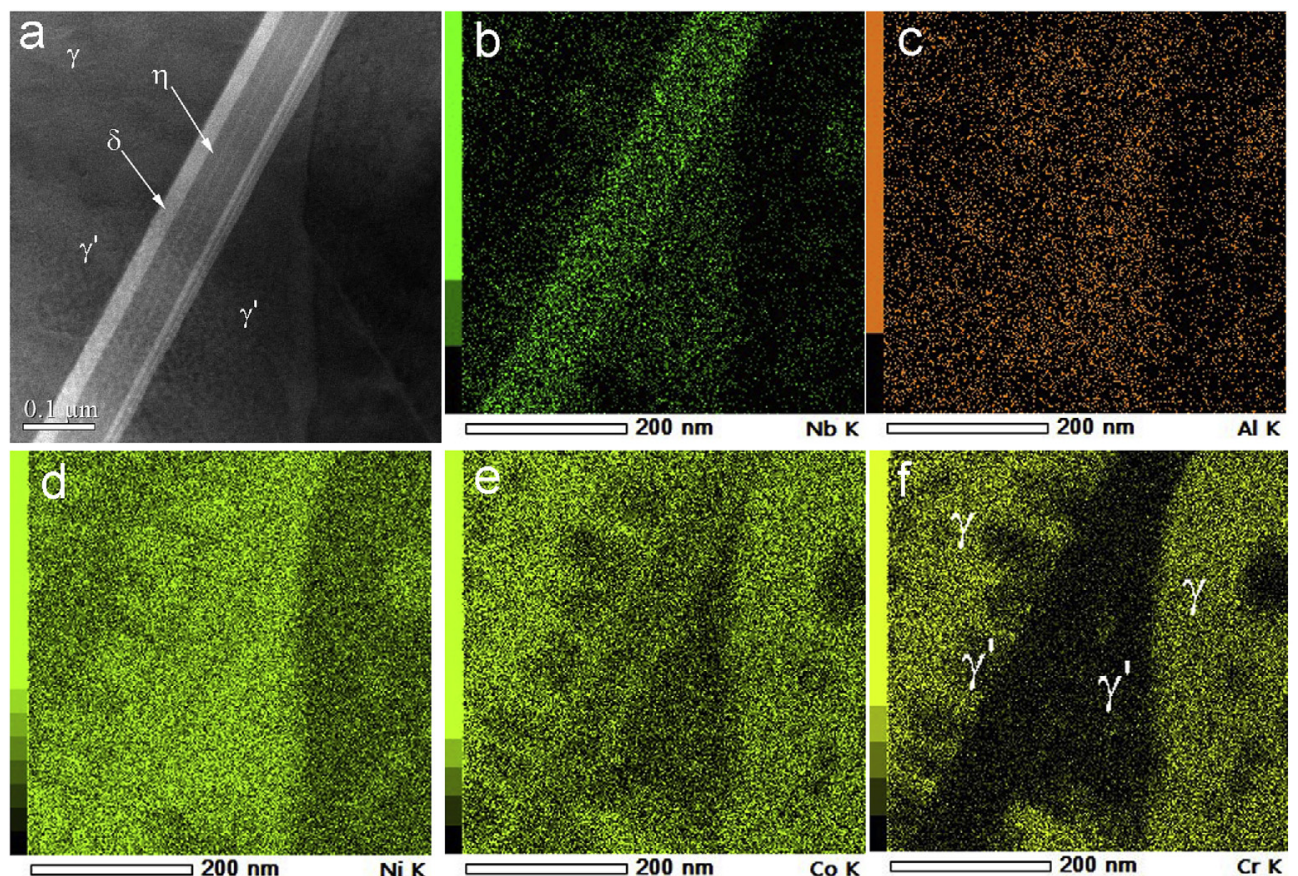

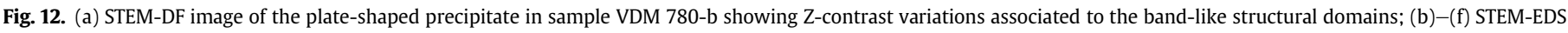
elemental maps showing the relative spatial distribution of $\mathrm{Nb}, \mathrm{Al}, \mathrm{Ni}, \mathrm{Co}$ and $\mathrm{Cr}$. 
between the adjacent $\delta$ and $\eta$ domains is described by $[010]_{\eta} \|$ $[100]_{\delta},(001)_{\eta}\left\|(010)_{\delta},(100)_{\eta}\right\|(001)_{\delta}$. In Fig. 11 we present a structural atomic model, obtained with the VESTA ${ }^{\mathrm{TM}}$ software, of the $\delta, \eta$ and $\gamma^{\prime}$ obeying the crystallographic orientation relationship deduced from the SAED and HRTEM analysis: $[010]_{\eta}\left\|[100]_{\delta}\right\|$ $[1-10]_{\gamma^{\prime}},(001)_{\eta}\left\|(010)_{\delta}\right\|(-1-11)_{\gamma^{\prime}}$. The two projections along the $[1-10]_{\gamma}$ and $[112]_{\gamma}$, axes of the $\gamma^{\prime}$ phase clearly illustrate the coherent crystallographic relationship between the $\delta / \eta$ plate-like precipitate and the $\{111\}_{\gamma}$, plane of the $\gamma^{\prime}$ phase. As the $\gamma^{\prime}$ phase precipitated within the $\gamma$ phase matrix during the furnace cooling step forming coherent precipitates [5], the same crystallographic relationship applies in the places where the $\delta / \eta$ precipitate (several microns long) comes in contact with the $\gamma$ phase grain. The structural model in Fig. 11 refers to the $\gamma^{\prime} / \delta / \eta$ situation, according to the analyzed SAED pattern and HRTEM micrograph in Figs. 9 and 10, but it is identical in the case of $\gamma / \delta / \eta$ where the $\gamma$ phase matrix is adjacent to the analyzed $\delta / \eta$ precipitate.

In order to analyze the local composition within and around the plate-shaped precipitate in sample VDM 780-b, we performed micro-analytical investigations in the STEM mode, using both the EDS and EELS spectroscopic techniques. The STEM-HAADF image of the plate-shaped precipitate oriented edge on is presented in Fig. 12a, showing that a $\mathrm{Z}$ contrast is associated to the band-like structural domains inside the precipitate. By comparatively examining the HRTEM and STEM images, the bands exhibiting a brighter STEM-DF contrast correspond to the $\delta$ phase stripes identified by HRTEM. The brighter STEM-DF contrast is associated with the presence of a heavier chemical element (higher $\mathrm{Z}$ ). To confirm this, we performed a chemical mapping of the area using the EDS technique. The elemental maps of the identified elements such as $\mathrm{Nb}, \mathrm{Al}, \mathrm{Ni}, \mathrm{Co}$ and $\mathrm{Cr}$ are presented in Fig. $12 \mathrm{~b}-\mathrm{f}$. According to the obtained chemical maps, Ni shows a rather complementary distribution with respect to $\mathrm{Co}$ and $\mathrm{Cr}$. A higher concentration of $\mathrm{Ni}$ can be observed inside limited areas surrounding the plate-shaped precipitate which correspond to the $\gamma^{\prime}$ phase. This fact is also confirmed by the SAED pattern recorded from a selected area adjacent to the precipitate (Fig. 9c), where the faint diffraction spots with even/odd Miller indices are clearly visible. The plateshaped precipitate shows a relatively higher concentration of $\mathrm{Nb}$, whereas the precipitate borders are slightly richer in $\mathrm{Nb}$ and $\mathrm{Co}$, while poorer in $\mathrm{Ni}$.

The same area was investigated also by EELS-SI in STEM mode using the same acquisition conditions as for the previous sample. For this purpose, an EEL spectrum was acquired in the 300-1300 eV spectral range in each image pixel within the frame marked as "Spectrum Image" in Fig. 13a (52 × 14 pixels, $2.8 \mathrm{~nm} /$ pixel $)$. The EEL spectra extracted from the whole data cube (Fig. 13b and c) contain the $\mathrm{Nb} \mathrm{M}_{4,5}$, Ti $\mathrm{L}_{3,2}, \mathrm{Cr} \mathrm{L}_{3,2}$, $\mathrm{Co}_{3,2}$ and $\mathrm{Ni} \mathrm{L}_{3,2}$ absorption edges that were used to map the spatial distribution of the mentioned elements. The STEM-EELS mapping confirms the results obtained by EDS regarding the $\mathrm{Nb}$ enrichment and the reduced concentration of $\mathrm{Ni}$ on the two lateral surfaces of the plate-shaped precipitate.

The chemical composition measured by EDS in various regions around the precipitate in sample VDM 780-b is provided in the Table 4 , indicating a higher abundance of $\mathrm{Nb}$ in the $\delta$ phase than the $\eta$ phase.

Comparing the microstructural results obtained on the analyzed high-temperature precipitates after the two types of heat treatment, some differences and similarities may be noticed. The hightemperature phases are rather well dispersed in the case of sample VDM 780-a and -b. They are more frequently observed in the latter case. This is due to the lower heat treatment temperature of $955^{\circ} \mathrm{C}$ as opposed to $975^{\circ} \mathrm{C}$, with the latter being already close to the solvus temperature of the high-temperature phases. In both analyzed samples, the high-temperature plate-like precipitates
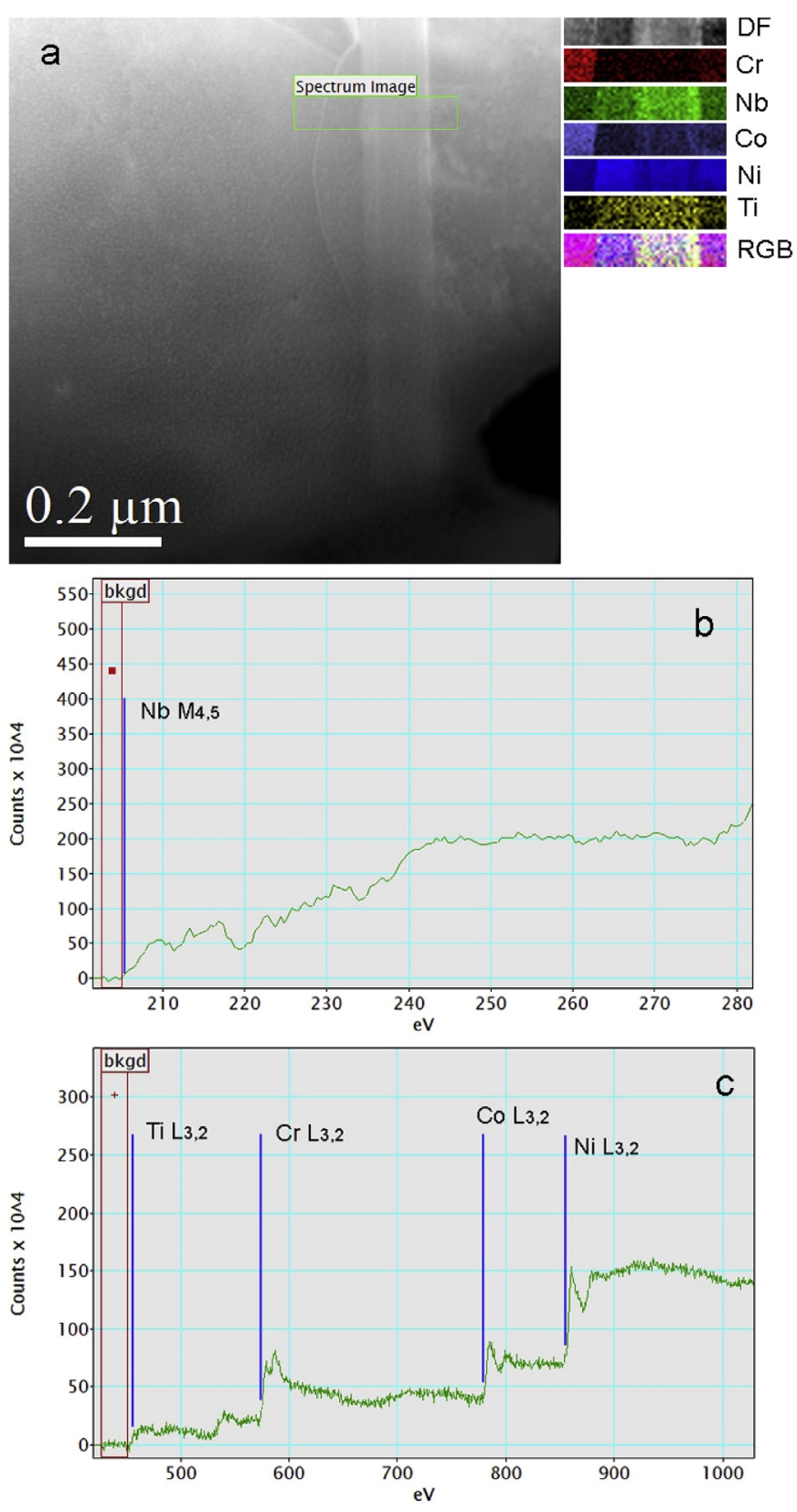

Fig. 13. (a) STEM-HAADF image pointing the area from which the EELS-SI was acquired in sample VDM 780-b; the DF image, the elemental maps and the composite image in false colors are presented next to it; (b), (c) EEL spectra extracted from the whole area showing the presence of $\mathrm{Nb}, \mathrm{Ti}, \mathrm{Cr}, \mathrm{Co}$ and $\mathrm{Ni}$. (For interpretation of the references to color in this figure legend, the reader is referred to the Web version of this article.)

consist in layered structures resulting from stacking of alternating thin plates packing of $\delta$ and $\eta$ phases. When measuring the width of the stripes corresponding to each phase there are some differences. It is found that for the precipitate analyzed in sample VDM 780-a the $\eta$ phase totalizes $208.5 \mathrm{~nm}$ and the $\delta$ phase about a half $(109 \mathrm{~nm})$, while the precipitate in sample VDM 780-b shows a total of $62 \mathrm{~nm}$ and $49 \mathrm{~nm}$ for the of $\eta$ and $\delta$ phases, respectively. Thus, the $\eta$ phase seems to be predominant with respect to $\delta$ in these precipitates, regardless of the sample, but to a much lesser extent (no more than twice as much) than the observations of Pickering et al. on the Allvac 718Plus alloy where they noticed the formation of only occasional narrow $\delta$ domains inside the $\eta$ phase precipitates [9] after a $72 \mathrm{~h}$ ageing treatment at $840{ }^{\circ} \mathrm{C}$. Moreover, for the VDM 
Table 4

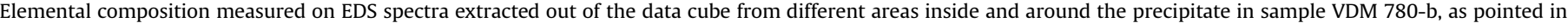
Fig. 12.

\begin{tabular}{|c|c|c|c|c|c|c|c|c|}
\hline Area & $\mathrm{Al} \mathrm{K}($ at \%) & Ti K (at \%) & $\mathrm{Cr} \mathrm{K}$ (at \%) & Fe K (at \%) & Co K (at \%) & $\mathrm{Ni} \mathrm{K}($ at \%) & $\mathrm{Nb} K($ at \%) & Mo K (at \%) \\
\hline$\gamma$ phase & 1.4 & 0.1 & 22.7 & 1.2 & 29.8 & 41.7 & 1.1 & 2.0 \\
\hline$\gamma^{\prime}$ phase & 4.2 & 0.8 & 4.5 & 0.8 & 14.8 & 68.3 & 6.3 & 0.3 \\
\hline Inside precipitate ( $\eta$ phase dominant) & 2.4 & 1.0 & 3.3 & 0.8 & 17.9 & 63.1 & 10.9 & 0.6 \\
\hline Precipitate border ( $\delta$ phase dominant) & 1.9 & 1.2 & 3.4 & 0.8 & 19.8 & 59.7 & 12.8 & 0.4 \\
\hline
\end{tabular}

780 Premium alloy, the coexistence of the $\delta$ and $\eta$ phases is systematically observed inside all the analyzed plate-like precipitates, while the volume ratio between the two high-temperature phases is rather well balanced, in the case of both thermal treatments applied. We will report on the mechanical properties of the VDM 780 Premium alloy and the influence of the high-temperature phase in an upcoming publication.

The chemical composition of the analyzed precipitates in both samples can be seen and compared from data shown in Tables 3 and 4 for samples VDM 780-a and b, respectively. The identified $\delta$ phase areas show a significant content of $\mathrm{Nb}$ (above $12 \%$ ), although below the nominal concentration in pure $\mathrm{Ni}_{3} \mathrm{Nb} \delta$ phase. At least partly, this is a result of the complex chemical composition with $\mathrm{Al}, \mathrm{Ti}, \mathrm{Cr}$ and Mo preferring the Nb-site [29]. In the VDM 780-b sample the $\delta$ domains show a lower Nb content than in the VDM 780-a alloy, although the performed measurements do not have a statistical relevance. The analyzed $\eta$ phase domains contain even lower quantities of $\mathrm{Ti}$ as compared to the nominal composition of the pure $\mathrm{Ni}_{3} \mathrm{Ti} \eta$ phase. In this case, $\mathrm{Nb}$ and $\mathrm{Al}$ are likely to occupy the $\mathrm{Ti}$ atomic positions. $\mathrm{Nb}$ and $\mathrm{Al}$ rich $\eta$ phases were reported previously in other alloys where the Ti atoms were replaced by $\mathrm{Nb}$ and $\mathrm{Al}$, partially or even completely, like in $\mathrm{Ni}_{6} \mathrm{AlNb}[30,31]$. This composition of the $\eta$ phase was also reported for the alloy 718Plus, with a solvus temperature of around $1010^{\circ} \mathrm{C}$ and similar effects on the mechanical properties of the alloy 718Plus as the $\delta$ phase has on the alloy 718: a moderate concentration inhibits the grain growth and the precipitation at the grain boundary promotes the alloy resistance to grain boundary creep fracture, while excessive amounts at the grain boundary reduce the strength and hardness of the alloy $[11,16]$.

The observed plate-shaped growth morphology of the hightemperature precipitates is due to the low interfacial energy
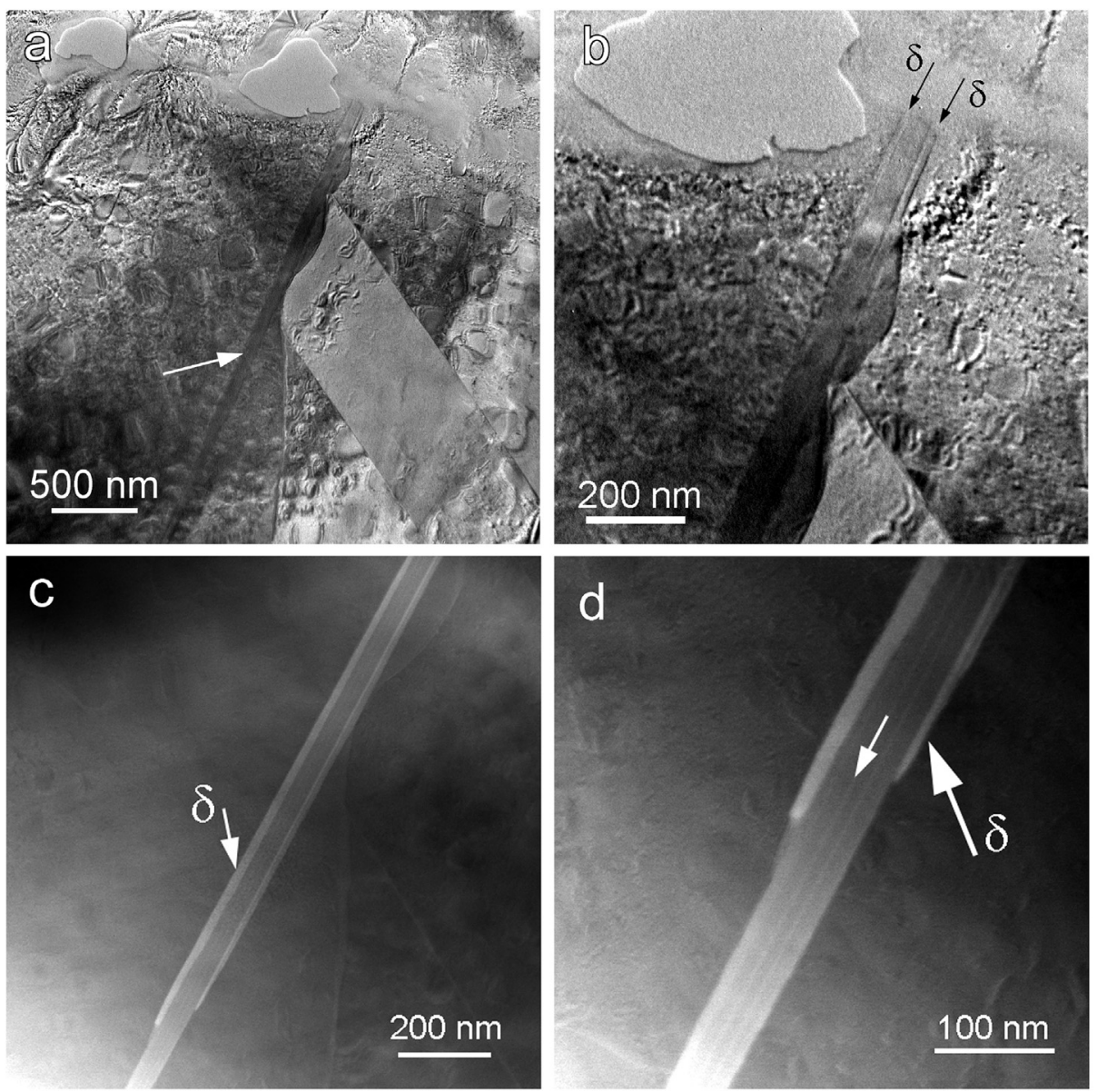

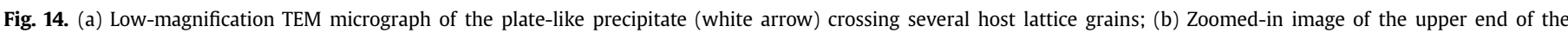

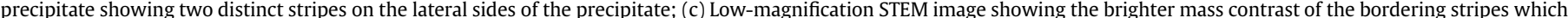

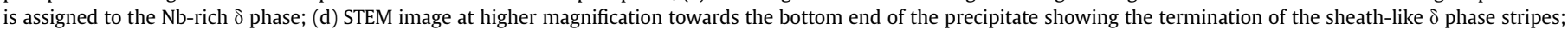
fine $\delta$ phase layers may be noticed inside the precipitate (pointed by the white arrow). 
between the $\gamma$ matrix and both high-temperature phase structures, [11,32]. The coexistence of two different phases within the same precipitate grain has been noticed by other authors [14,33-35] also in the case of $\mathrm{Cr}$ or $\mathrm{Ni}$ alloys. The parallel formation of the two adjacent phases seems to be related to the local chemical composition and the accommodation of the strain within the host lattice. It is important to note here that the stress between the precipitate and the host lattice is relieved by dislocations. These dislocations are piled up at the precipitate-matrix interface, while only a few can be noticed inside the precipitate. It is likely that the two phases nucleate and grow together as long as the local $\mathrm{Nb}$ abundance allows the formation of the $\delta$ phase. While the thickness of the $\delta$ and $\eta$ slabs varies, in general between 1.5 and $100 \mathrm{~nm}$, we did not notice any particular rule regarding the thickness and the positioning of the $\delta$ or $\eta$ stripes within or on the border of the precipitates. Relatively thick $\delta$ phase stripes $(20-50 \mathrm{~nm})$ may be formed both inside and at the boundary of the analyzed precipitates. The formation of the $\delta$ phase seems to be conditioned by the local content of $\mathrm{Nb}$, and it may cease once the local $\mathrm{Nb}$ content drops. The lowmagnification STEM image showed in Fig. 14 illustrates the situation in which the lateral Nb-rich $\delta$ phase stripes bordering the plate-like precipitate come to an end while the $\eta$ phase core of the precipitate continued to grow. An attractive experimental study that could be extremely useful to obtain a more complete picture of the VDM 780 Premium alloy behaviour in terms of nucleation and growth of the high-temperature $\delta / \eta$ precipitates could be to perform in situ heat treatments under the electron microscope.

\section{Conclusions}

X-ray diffraction with synchrotron radiation clearly shows the coexistence of $\delta$ and $\eta$ phase in the newly developed Ni base superalloy VDM 780 Premium. For an in-depth study of the microstructure and morphology of these high-temperature phases, their fine structure was investigated by high-resolution transmission electron microscopy and associated analytical techniques. The analyzed samples were submitted to two different thermal treatments leading to different conditions for the formation of the hightemperature precipitates, essentially in the absence or the presence of the $\gamma^{\prime}$ strengthening phase. Our results corroborated from SAED patterns, HRTEM imaging and local FFT diagrams have revealed that in both situations the high-temperature precipitates in the alloy VDM 780 Premium exhibit a layered structure consisting of alternating $\delta$ and $\eta$ phases in the crystallographic orientation relationship $[010]_{\eta}\left\|[100]_{\delta},(001)_{\eta}\right\|(010)_{\delta},(100)_{\eta} \|(001)_{\delta}$. The thickness of the plate-like precipitates varies from one sample to the other due to the different temperature history. The $\eta$ phase is preponderant (around twice as much) inside the precipitates with respect to the $\delta$ phase, with a significant quantitative increase of the $\delta$ phase in comparison to Allvac 718Plus. The chemical composition of the $\delta$ and $\eta$ stripes shows a deficit of $\mathrm{Nb}$ or Ti compared to the nominal stoichiometries $\mathrm{Ni}_{3} \mathrm{Nb}$ and $\mathrm{Ni}_{3} \mathrm{Ti}$ of the $\delta$ and $\eta$ phases, respectively. As mentioned before, this can be attributed, at least partly, to the occupation of $\mathrm{Nb}$ - and Ti-sites by other elements such as Al. Possibly, insufficient Nb-supply, being trapped inside the $\gamma / \gamma^{\prime}$ phase, due to a diffusion limited growth process may have played a further role. Besides, the formation of the $\delta$ phase seems to be conditioned by the local content of $\mathrm{Nb}$, and it may cease once the local Nb content drops.

\section{Acknowledgements}

We acknowledge DESY (Hamburg, Germany), a member of the Helmholtz Association HGF, for the provision of experimental facilities. Parts of this research were carried out at PETRA III and we would like to thank Norbert Schell and Emad Maawad for assistance in using HEMS beamline. Furthermore, the authors acknowledge the CERIC-ERIC Consortium for the access to experimental facilities (at the National Institute of Materials Physics in Romania) and financial support. Financial support of this work via the BMBF Project 05K16WO2 is kindly acknowledged. C.G. acknowledges the financial support from Romanian Ministry of Research and Innovation in the frame of the Core Program PN19-03.

\section{Appendix A. Supplementary data}

Supplementary data to this article can be found online at https://doi.org/10.1016/j.jallcom.2019.152157.

\section{References}

[1] T.M. Pollock, S. Tin, Nickel-based superalloys for advanced turbine engines: chemistry, microstructure and properties, J. Propuls. Power 22 (2006) $361-374$.

[2] D. Furrer, H. Fecht, Ni-based superalloys for turbine discs, J. Miner. Met. Mater Soc. 51 (1999) 14-17.

[3] J.N. Wagner, M. Hofmann, S. Van Petegem, C. Krempaszky, M. Hoelzel, M. Stockinger, Comparison of intergranular strain formation of conventional and newly developed nickel based superalloys, Mater. Sci. Eng. A 662 (2016) 303-307.

[4] T. Fedorova, J. Rösler, B. Gehrmann, J. Klöwer, Invention of a new 718-type NiCo superalloy familiy for high temperature applications at $750^{\circ} \mathrm{C}$, in: E. Ott, A. Banik, J. Andersson, I. Dempster, T. Gabb, J. Groh, K. Heck, R. Helmink, X. Liu, A. Wusatowska-Sarnek (Eds.), 8th International Symposium on Superalloy 718 and Derivatives, TMS, 2014, pp. 587-599.

[5] T. Fedorova, J. Rösler, J. Klöwer, B. Gehrmann, Development of a new 718-type $\mathrm{Ni}-\mathrm{Co}$ superalloy family for high temperature application at $750^{\circ} \mathrm{C}$, MATEC Web Conf. 14 (2014), 01003.

[6] C. Solís, J. Munke, M. Bergner, A. Kriele, M.J. Mühlbauer, D.V. Cheptiakov, B. Gehrmann, J. Rösler, R. Gilles, In situ characterization at elevated temperatures of a new Ni-based superalloy VDM-780 premium, Metall. Mater. Trans. A 49 (2018) 4373-4381.

[7] M. Bergner, J. Rösler, B. Gehrmann, J. Klöwer, Effect of heat treatment on microstructure and mechanical properties of VDM alloy 780 Premium, in: E. Ott, et al. (Eds.), Proceedings of the $9^{\text {th }}$ International Symposium on Superalloy 718 \& Derivatives: Energy, Aerospace, and Industrial Applications. The Minerals, Metals \& Materials Series, Springer, Cham, 2018, ISBN 978-3319-89479-9, pp. 489-499.

[8] C. Solís, J. Munke, M. Hofmann, S. Mühlbauer, M. Bergner, B. Gehrmann, J. Rösler, R. Gilles, In-situ characterization at high temperature of VDM alloy 780 Premium to determine solvus temperatures and phase transformations using neutron diffraction and small-angle neutron scattering, in: B. Li, et al. (Eds.), Characterization of Minerals, Metals, and Materials 2019, the Minerals, Metals \& Materials Series, 2019, ISBN 978-3-030-05748-0, pp. 23-32, https:// doi.org/10.1007/978-3-030-05749-7_3.

[9] C. Stotter, C. Sommitsch, J. Wagner, H. Leitner, I. Letofsky-Papst, G. Zickler, W. Prantl, M. Stockinger, Characterization of $\delta$-phase in superalloy allvac 718PlusTM, Int. J. Mater. Res. 99 (2008) 376-380.

[10] L. Viskari, K. Stiller, Atom probe tomography of Ni-base superalloys Allvac718 plus and alloy718, Ultramicroscopy 111 (2011) 652-658.

[11] E.J. Pickering, H. Mathur, A. Bhowmik, O.M.D.M. Messé, J.S. Barnard, M.C. Hardy, R. Krakow, K. Loehnert, H.J. Stone, C.M.F. Rae, Grain-boundary precipitation in allvac 718Plus, Acta Mater. 60 (2012) 2757-2769.

[12] A. Kruk, G. Cempura, S. Lech, A. Czyrska -Filemonowic, STEM-EDX and FIBSEM tomography of Allvac 718Plus superalloy, Arch. Metall. Mater. 61 (2016) 535-542.

[13] R. Krakow, D.N. Johnstone, A.S. Eggeman, D. Hünert, M.C. Hardy, C.M.F. Rae P.A. Midgley, On the crystallography and composition of topologically close-

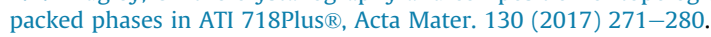

[14] O.M. Messé, J.S. Barnard, E.J. Pickering, P.A. Midgley, C.M.F. Rae, On the precipitation of delta phase in ALLVAC $($ 718Plus, Philos. Mag. 94 (2014) 1132-1152.

[15] T.M. Smith, B.D. Esser, N. Antolin, A. Carlsson, R.E.A. Williams, A. Wessman, T. Hanlon, H.L. Fraser, W. Windl, D.W. McComb, M.J. Mills, Phase transformation strengthening of high-temperature superalloys, Nat. Commun. 7 (2016), 13434.

[16] M. Wang, J. Du, Q. Deng, Z. Tian, J. Zhu, Effect of the precipitation of the $\eta-$ $\mathrm{Ni}_{3} \mathrm{Al}_{0.5} \mathrm{Nb}_{0.5}$ phase on the microstructure and mechanical properties of ATI 718Plus, J. Alloy. Comp. 701 (2017) 635-644.

[17] C. Slama, M. Abdellaoui, Structural characterization of the aged inconel 718, J. Alloy. Comp. 306 (2000) 277-284.

[18] D. Del Genovese, P. Strunz, D. Mukherji, R. Gilles, J. Rösler, Microstructural characterization of a modified 706-type Ni-Fe superalloy by small-angle neutron scattering and electron microscopy, Metall. Mater. Trans. A 36 (2005) 3439-3450. 
[19] M. Fisk, J. Andersson, R. du Rietz, S. Haas, S. Hall, Precipitate evolution in the early stages of ageing in Inconel 718 investigated using small-angle X-ray scattering, Mater. Sci. Eng. A 612 (2014) 202-207.

[20] M. Detrois, S. Antonov, R.C. Helmink, S. Tin, Precipiste, precipitate phase stability in $\gamma-\gamma^{\prime}-\delta-\eta$ Ni-base superalloys, JOM (J. Occup. Med.) 66 (2014) $2478-2485$.

[21] S. Antonov, M. Detrois, R.C. Helmink, S. Tin, Precipitate phase stability and compositional dependence on alloyingadditions in $\gamma-\gamma^{\prime}-\delta-\eta$ Ni-base superalloys, J. Alloy. Comp. 626 (2015) 76-86.

[22] T. N. Schell, A. King, F. Beckmann, T. Fischer, M. Müller, A. Schreyer, The high energy materials science beamline (HEMS) at PETRA III Mater. Sci. Forum 772 (2014) 57-61.

[23] A.P. Hammersley, FIT2D: a multi-purpose data reduction, analysis and visualization program, J. Appl. Crystallogr. 49 (2016) 646-652.

[24] J. Rodríguez-Carvajal, Recent advances in magnetic structure determination by neutron powder diffraction, Phys. B Condens. Matter 192 (1993) 55-69.

[25] H.M. Rietveld, A profile refinement method for nuclear and magnetic structures, J. Appl. Crystallogr. 2 (1969) 65-71.

[26] P. Kontis, A. Kostka, D. Raabe, B. Gault, Influence of composition and precipitation evolution on damage at grain boundaries in a crept polycrystalline $\mathrm{Ni}$ based superalloy, Acta Mater. 166 (2019) 158-167.

[27] M.J. Hÿtch, E. Snoeck, R. Kilaas, Quantitative measurement of displacement and strain fields from HREM micrographs, Ultramicroscopy 74 (1998)
$131-146$.

[28] M.J. Hÿtch, J.-L. Putaux, J.-M. Pénisson, Measurement of the displacement field around dislocations to $0.03 \AA$ by electron microscopy, Nature 423 (2003) $270-273$.

[29] M. Bäker, J. Rösler, T. Hentrich, G. Ackland, Influence of transition group elements on the stability of the $\delta$ - and $\eta$-phase in nickel base alloys, Model. Simul. Mater. Sci. Eng. 26 (2018), 015005.

[30] B.C. Giessen, N.J. Grant, New intermediate phases in transition metal systems. II, Acta Crystallogr. 18 (1965) 1080-1081.

[31] K. Tomihisa, Y. Kaneno, T. Takasugi, Phase relation and microstructure in $\mathrm{Ni}_{3} \mathrm{Al}-\mathrm{Ni}_{3} \mathrm{Ti}-\mathrm{Ni}_{3} \mathrm{Nb}$ pseudo-ternary alloy system, Intermetallics 10 (2002) $247-254$.

[32] I. Kirman, Precipitation in the Fe-Ni-Cr-Nb system, J. Iron Steel Inst. 207 (1969) 1612-1618.

[33] Y.-L. Hu, A. Vasiliev, L. Zhang, K. Song, M. Aindow, Polymorphism in the Lavesphase precipitates of a quinternary $\mathrm{Nb}-\mathrm{Mo}-\mathrm{Cr}-\mathrm{Al}-\mathrm{Si}$ alloy, Scr. Mater. 60 (2009) 72-75

[34] K.S. Kumar, L. Pang, C. Liu, J. Horton, E. Kenik, Structural stability of the Laves phase $\mathrm{Cr}_{2} \mathrm{Ta}$ in a two-phase $\mathrm{Cr}-\mathrm{Cr}_{2}$ Ta alloy, Acta Mater. 48 (2000) 911-923.

[35] A. Proult, P. Donnadieu, Identification of the fault vectors of planar defects in the sigma phase of a nickel-based superalloy, Philos. Mag. A 72 (1995) 403-414. 